\title{
Transferring Lithium lons in the Nanochannels of Flexible Metal- Organic Frameworks Featuring Superchaotropic Metallacarborane Guests: Mechanism of Ionic Conductivity at the Atomic Resolution
}

\author{
Jiri Brus, ${ }^{a^{*}}$ Jiri Czernek, ${ }^{a}$ Martina Urbanova, ${ }^{a}$ Jan Rohlíček, ${ }^{b}$ and Tomáš Plecháček ${ }^{c}$ \\ a) Czech Academy of Sciences, Institute of Macromolecular Chemistry, Heyrovský sq. 2, 16206 Prague 6, Czech \\ Republic \\ b) Institute of Physics of the Czech Academy of Sciences, Na Slovance 1999/2, Prague 8182 21, Czech Republic \\ c) University of Pardubice, Faculty of Chemical Technology, Joint Laboratory of Solid-State Chemistry, Studentska \\ 84, 53210 Pardubice, Czech Republic
}

AUTHOR EMAIL ADDRESSES: brus@imc.cas.cz, czernek@imc.cas.cz, urbanova@imc.cas.cz, rohlicek@fzu.cz, Tomas.Plechacek@upce.cz

\section{Table of Content}

Supporting Information S1 - Materials and sample preparation

Supporting Information S2 - Solid-State NMR Spectroscopy, PXRD and AC conductivity measurements

Supporting Information S3 - Quantum chemical calculations of ${ }^{27} \mathrm{Al}$ NMR parameters

Supporting Information S4 - Analysis of ${ }^{27}$ AI MAS NMR spectra

Supporting Information S5 - Analysis of motion-averaged ${ }^{1} \mathrm{H}-{ }^{13} \mathrm{C}$ one-bond dipolar couplings

Supporting Information S6-2D ${ }^{7} \mathrm{Li}-{ }^{7} \mathrm{Li} \mathrm{DQ} / \mathrm{SQ}$ NMR spectra

Supporting Information S7 - ${ }^{7} \mathrm{Li}-{ }^{7} \mathrm{Li} \mathrm{DQ}$ coherence build-ups and ${ }^{7} \mathrm{Li}{ }^{7} \mathrm{Li}$ interatomic distances

Supporting Information S8 - ${ }^{7} \mathrm{Li}-{ }^{7} \mathrm{Li}$ Exchange Spectroscopy (EXSY)

Supporting Information S9 - AC conductivity measurements

Supporting Information S10 - Powder X-ray diffraction data 
Materials. Lithium salt of metallacarborane anion [3-cobalt(III) bis(1,2-dicarbollide)](-1), $\mathrm{Li}^{+} \mathrm{COD}^{-}$, was purchased from Katchem Ltd, Czech Republic. Metal-organic framework MIL53(AI) was purchased from Sigma-Aldrich (Czech Republic) under the trade mark Basolite ${ }^{\circledR}$ A100. The purchased MIL53(Al) was activated 24 hours at $150^{\circ} \mathrm{C}$. This way the residual 1,4-benzendicarboxyl acid and water molecules were removed as indicated by the disappearance of the weak signal at $174.8 \mathrm{ppm}$ in ${ }^{13} \mathrm{C} \mathrm{CP} / \mathrm{MAS}$ NMR spectra (Figure S1a). Nearly negligible amount of residual impurities, less than $0.5 \mathrm{wt}$. \%, was indicated by thermogravimetric analysis (TGA). The absence of water molecules was further verified by the ${ }^{1} \mathrm{H}$ CRAMPS NMR spectrum in which only the signals of aromatic protons and $-\mathrm{Al}(\mathrm{OH})$ - protons resonating at 7.3 and $1.8 \mathrm{ppm}$, respectively, were detected (Figure S1b).
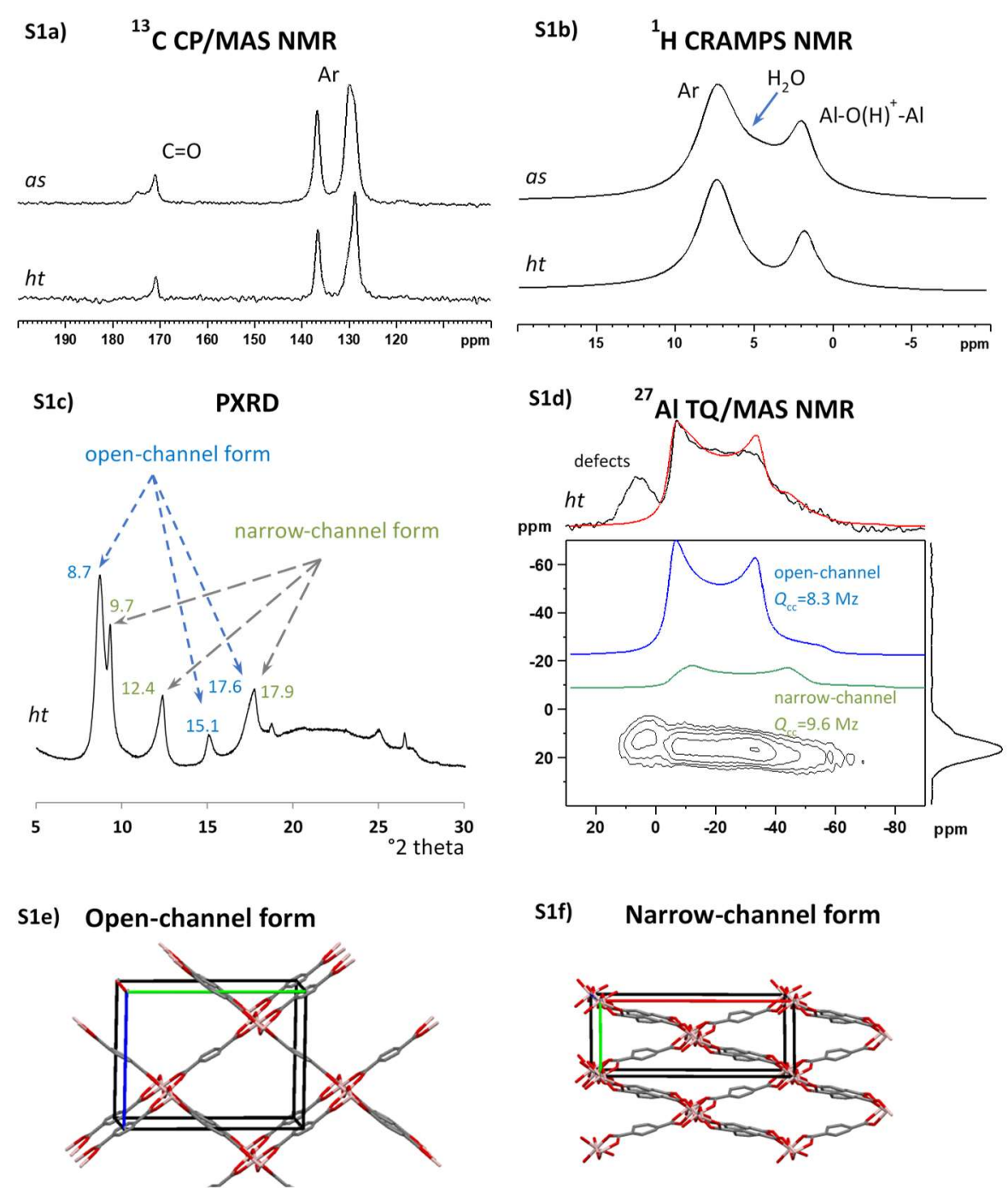

\section{S1f) Narrow-channel form}

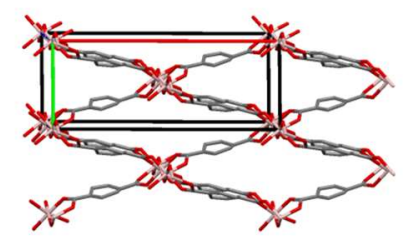

Figure S1. ${ }^{13} \mathrm{C}$ CP/MAS and ${ }^{1} \mathrm{H}$ CRAMPS NMR spectra of the as-purchased (as) and thermally activated (ht) MIL(53Al) framework, (a) and (b) respectively; PXRD data and 2D ${ }^{27} \mathrm{Al}$ TQ/MAS NMR spectrum recorded for the thermally activated (ht) MIL(53Al) framework, (c) and (d) respectively; and the crystal structures of MIL(53Al) open-channel framework and narrow-channel framework, (d) and (f) respectively.

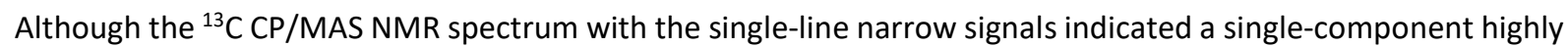
crystalline material, the PXRD data (Figure S1c) revealed presence of two distinctly different polymorphic forms of MIL53(AI) framework. Following the literature data ${ }^{1}$ the intensive $x$-ray reflection at $8.7^{\circ} 2 \theta$ shows that the initial thermally-activated MIL53(Al) framework consisted predominantly of the open-channel polymorphic form (ca. 70-80\%) with the units-cell parameters $a ; b$; and $c=6.6 ; 16.76$; and $12.73 \AA$. The low-intensive sharp x-ray 
reflection at $9.7^{\circ} 2 \theta$ than indicates that this main phase is accompanied by the secondary narrow-channel polymorphic form (ca. 30-20 \%) the units-cell parameters of which are $a ; b$; and $c=6.6 ; 16.76$; and $12.73 \AA$. The system further exhibits presence of ca. $10 \%$ of disordered or amorphous fraction. As extracted from the $2 \mathrm{D}{ }^{27} \mathrm{Al}$ TQ/MAS NMR spectrum (Figure S1d) the ${ }^{27} \mathrm{Al}$ NMR parameters (isotropic chemical shift $\delta_{\mathrm{sis}}\left({ }^{27} \mathrm{Al}\right)=3.5-2.8 \mathrm{ppm}$ and quadrupolar coupling constant $Q_{c c}=8.7-8.2 \mathrm{MHz}$ ) additionally confirm the prevailing open-channel character of the thermally-activated MIL53(Al) framework (Figure S1e). The secondary (narrow-channel) fraction (Figure S1f) is than indicated by the low-intensive signal at ca. $3.5 \mathrm{ppm}$ with the quadrupolar coupling constant $C_{Q}$ of ca. 9.39.5 $\mathrm{MHz}$. This value is slightly smaller in comparison with the $C_{Q}$ previously determined for the narrow-channel polymorph $\left(\mathrm{C}_{\mathrm{Q}}=10.67 \mathrm{MHz}\right.$ for $\left.\mathrm{MIL53}(\mathrm{Al}) / t\right) .{ }^{1}$ The observed difference follows from the fact that previously the narrow-channel form was extensively hydrated, whereas in the current state the water molecules are removed. The quantum chemical calculations described in Supporting Information S3 then revealed that by removing the water molecules from the narrow-pore structure the quadrupolar coupling constants decrease by ca. $1 \mathrm{MHz}$.

Preparation of MIL53(Al)@LiCoD composites. MIL53(Al)ht material (30 mg) was suspended in spectroscopically pure ethanol $(3.5 \mathrm{~mL})$. The obtained suspension was added to $3.5 \mathrm{~mL}$ solution of LiCoD in spectroscopically pure ethanol. The amount of LiCoD varied from 10 to $100 \mathrm{mg}$. The resulting mixture was maintained under stirring at $60{ }^{\circ} \mathrm{C}$ for 1-7 days. Once filtered and recovered, the resulting MIL53(AI)@LiCoD material was dried. The whole synthesis took place under argon atmosphere. The synthesis was followed by 24 hours drying under vacuum at $50^{\circ} \mathrm{C}$. Total amount of LiCoD incorporated into the MIL53(Al) framework was estimated from the recorded ${ }^{13} \mathrm{C}$ CP/MAS NMR spectra by signal integration. The absence of residual absorbed water and disordered 1,4-

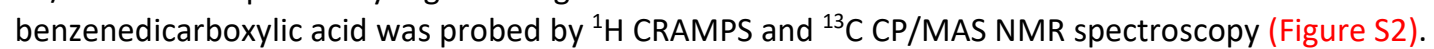
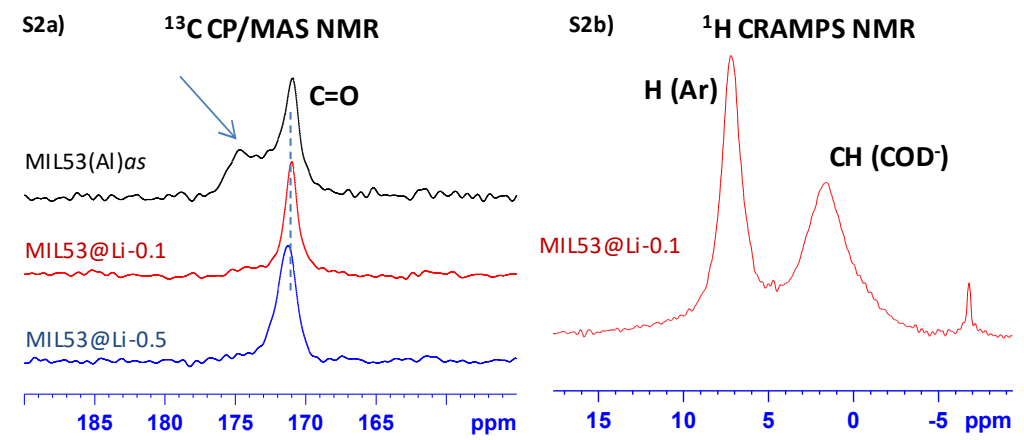

Figure S2. ${ }^{13} \mathrm{C} \mathrm{CP} / \mathrm{MAS}$ spectra of the as-purchased MIL(53Al) framework and host-guest composites MIL53(Al)@LiCoD-0.10 and MIL53(Al)@LiCoD-0.50 (a); and ${ }^{1} \mathrm{H}$ CRAMPS NMR spectrum of the host-guest composite MIL53(Al)@LiCoD-0.10 (b).

\section{References:}

(1) Thierry Loiseau, Christian Serre, Clarisse Huguenard, Gerhard Fink, Francis Taulelle, Marc Henry, Thierry Bataille, Gérard Férey, A Rationale for the Large Breathing of the Porous Aluminum Terephthalate (MIL53) Upon Hydration, Chem. Eur. J. 2004, 10, 1373 - 1382. https://doi.org/10.1002/chem.200305413 
Supporting Information S2 - Solid-State NMR Spectroscopy, PXRD and conductivity measurements

Solid-state NMR spectra were measured at 11.7 T on a Bruker Avance III HD 500 US/WB NMR spectrometer (Karlsruhe, Germany, 2013). The following techniques were applied:

i) one-dimensional (1D) ${ }^{1} \mathrm{H},{ }^{7} \mathrm{Li},{ }^{11} \mathrm{~B},{ }^{13} \mathrm{C}$ and ${ }^{27} \mathrm{Al}$ MAS and optionally CP/MAS NMR experiments;

ii) $1 \mathrm{D}^{1} \mathrm{H}$ CRAMPS NMR experiments with DUMBO homodecoupling; ${ }^{2}$

iii) two-dimensional (2D) ${ }^{1} \mathrm{H}-{ }^{13} \mathrm{C}\left({ }^{11} \mathrm{~B}\right)$ separated-local-field (SLF) PILGRIM experiments; ${ }^{3}$

iv) $2 \mathrm{D}^{1} \mathrm{H}-{ }^{13} \mathrm{C}\left({ }^{7} \mathrm{Li},{ }^{11} \mathrm{~B},{ }^{27} \mathrm{Al}\right) \mathrm{FSLG}$ HETCOR experiments; ${ }^{4}$

v) $2 \mathrm{D}^{7} \mathrm{Li}-{ }^{7} \mathrm{Li}$ exchange spectroscopy experiment ${ }^{5}\left(2 \mathrm{D}^{7} \mathrm{Li}-{ }^{7} \mathrm{Li}\right.$ EXSY MAS NMR);

vi) $2 \mathrm{D}^{7} \mathrm{Li}-{ }^{7} \mathrm{Li}$ exchange spectroscopy experiment with ${ }^{1} \mathrm{H}-{ }^{7} \mathrm{Li}$ cross polarization (2D ${ }^{7} \mathrm{Li}-{ }^{7} \mathrm{Li}$ EXSY $\mathrm{CP} / \mathrm{MAS} N \mathrm{NMR}$ );

vii) $2 \mathrm{D}^{7} \mathrm{Li}-{ }^{7} \mathrm{Li}$ double-quantum (DQ) experiments ${ }^{6,7}$ with the $\mathrm{BR} 212$ recoupling sequence ${ }^{8,9}\left(2 \mathrm{D}{ }^{7} \mathrm{Li}-{ }^{7} \mathrm{Li} \mathrm{DQ} / \mathrm{SQ}\right.$ MAS NMR);

viii) variable-temperature saturation-recovery spin-lattice relaxation experiments $T_{1}\left({ }^{7} \mathrm{Li}\right)$; and

ix) ${ }^{27} \mathrm{Al}$ triple-quantum (TQ) MAS NMR experiments. ${ }^{10}$

The frictional heating ${ }^{11,12}$ of the spinning samples was compensated by active cooling, and the temperature calibrations were performed with $\mathrm{Pb}\left(\mathrm{NO}_{3}\right)_{2}$. Details are described below.

1D MAS NMR experiments: All solid-state NMR spectra were measured at $11.7 \mathrm{~T}$ using a Bruker Avance 500 WB/US NMR spectrometer (2013) in double-resonance 4- $\mathrm{mm}$ and 3.2-mm probe-heads at spinning frequencies $10-25 \mathrm{kHz}$. The ${ }^{7 \mathrm{Li}}{ }^{11} \mathrm{~B}$ and ${ }^{27} \mathrm{Al} \mathrm{MAS} N M R$ spectra were acquired at $194.38,160.42$ and $130.33 \mathrm{MHz}$, respectively; spinning frequency was $\omega_{r} / 2 \pi=20 \mathrm{kHz} ; 20^{\circ}$ pulse width was $1 \mu \mathrm{s}$; recycle delay of $2-4 \mathrm{~s}$; and the number of scans was 64-128. The ${ }^{11} \mathrm{~B}$ scale was calibrated with external standard - borax (disodium tetraborate, $\left.\mathrm{Na}_{2}\left[\mathrm{~B}_{4} \mathrm{O}_{5}(\mathrm{OH})_{4}\right] \cdot 8 \mathrm{H}_{2} \mathrm{O}\right)$; signal of $\mathrm{B}^{\prime \prime \prime}$ at $\left.1.5 \mathrm{ppm}\right)$. The ${ }^{7} \mathrm{Li}$ scale was calibrated with external standard $-\mathrm{LiCl}$ crystalline (-1.04 ppm). The ${ }^{27} \mathrm{Al}$ scale was calibrated with external standard - $\mathrm{AlNO}_{3}$ (aq.) $(0.0 \mathrm{ppm})$. The ${ }^{13} \mathrm{C}$ $\mathrm{CP} / \mathrm{MAS} N \mathrm{NR}$ spectra employing cross-polarization were acquired using the standard pulse scheme at spinning frequency of $11-20 \mathrm{kHz}$. The recycle delay was $4 \mathrm{~s}$ and the cross-polarization contact time was 1-2 ms. The strength of spin-locking fields $B_{1}\left({ }^{13} \mathrm{C}\right)$ expressed in frequency units $\omega_{1} / 2 \pi=\gamma B_{1}$ was $64 \mathrm{kHz}$. The spectra were referenced to $\alpha$-glycine (176.03 ppm). The ${ }^{1} \mathrm{H}$ CRAMPS NMR spectra with DUMBO homodecoupling were measured at $10 \mathrm{kHz}$ (MAS frequency) and number of scans $16-128$. The $90^{\circ}\left({ }^{1} \mathrm{H}\right)$ pulse-length was $2.2 \mu \mathrm{s}$, power level for DUMBO shape pulse was $71 \mathrm{~W}$, DUMBO pulse length $32 \mu$ s and the number of loops for digital averaging was 4-8. All parameters were optimized on glycine to reach maximum spectral resolution $\left(\Delta v\left(\mathrm{NH}_{3}{ }^{+}\right)=250 \mathrm{~Hz}\right.$ and $\Delta v\left(\mathrm{CH}_{2}\right)=230 \mathrm{~Hz}$, Figure S3). The ${ }^{1} \mathrm{H}$ scale was calibrated with external standard - alanin (low-field $\mathrm{NH}_{3}$ signal at $8.5 \mathrm{ppm}$ and the high field $\mathrm{CH}_{3}$ signal at $1.2 \mathrm{ppm}$.

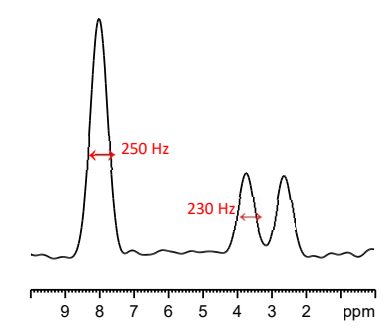

Figure S3. ${ }^{1} \mathrm{H}$ CRAMPS NMR spectrum $(10 \mathrm{kHz})$ of glycine.

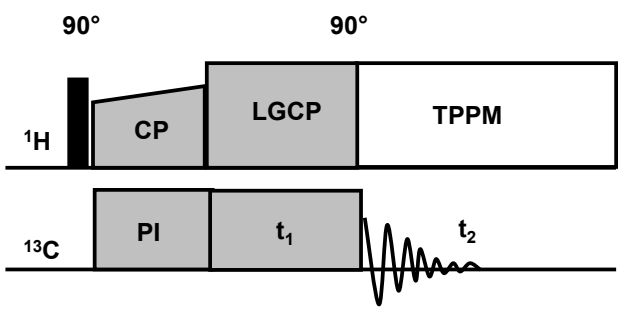

Figure S4. Schematic representation of $2 \mathrm{D}{ }^{1} \mathrm{H}-{ }^{13} \mathrm{C}$ PILGRIM experiment.

$2 D^{1} \mathrm{H}_{-}^{13} \mathrm{C}\left({ }^{11} \mathrm{~B}\right)$ SLF PILGRIM MAS NMR: The site-specific measurement of one-bond ${ }^{1} \mathrm{H}-{ }^{13} \mathrm{C}$ and ${ }^{1} \mathrm{H}-{ }^{11} \mathrm{~B}$ dipolar couplings under the Lee-Goldburg condition was achieved by the 2D PILGRIM experiment (Figure S4). The length of polarization-inversion period was $1 \mathrm{~ms}$. Lee-Goldburg cross polarization was incremented from 50 to $5170 \mu \mathrm{s}$ with $20 \mu$ s increment. The experiments were performed at spinning frequency $\omega_{r} / 2 \pi=12.5 \mathrm{kHz}$. The recycle delay was $4 \mathrm{~s}, \mathrm{t}_{1}$ evolution period consisted of 256 increments each made of 512 scans. 
$2 D^{1} \mathrm{H}^{13} \mathrm{C}\left({ }^{7} \mathrm{Li}^{11} \mathrm{~B}^{127} \mathrm{Al}\right) \mathrm{FSLG}$ HETCOR MAS NMR experiments: Two-dimensional (2D) ${ }^{1} \mathrm{H}-{ }^{13} \mathrm{C}$ HETCOR experiments were performed using the FSLG (Frequency Switched Lee-Goldburg) decoupling during the $t_{1}$ evolution period consisting of 64-128 increments each made of 128-512 scans with a dwell time of $42.6 \mu$ s (Figure S5). Rotation frequency was $\omega_{r} / 2 \pi=12.5 \mathrm{kHz}$. The $B_{1}\left({ }^{1} \mathrm{H}\right)$ field strength of FSLG and SPINAL-64 decoupling expressed in frequency units $\omega_{1} / 2 \pi=\gamma B_{1}$ was $89.3 \mathrm{kHz}$.

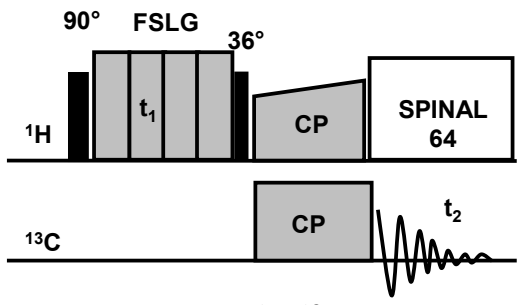

Figure S5. Schematic representation of $2 \mathrm{D}{ }^{1} \mathrm{H}-{ }^{13} \mathrm{C}$ FSLG HETCOR MAS NMR experiment.

${ }^{7} \mathrm{Li}-{ }^{7} \mathrm{Li}$ EXSY NMR: The 2D ${ }^{7} \mathrm{Li}-{ }^{7} \mathrm{Li}$ EXSY correlation spectra were measured using two different experimental arrangements. Primarily, the standard three-pulse (NOESY-type) pulse sequence (Figure S6a) was applied. Alternatively, the EXSY experiment employing ${ }^{1} \mathrm{H}-{ }^{7} \mathrm{Li}$ cross-polarization instead of a single-pulse excitation was applied (Figure S6b). The spinning frequency of $\omega_{r} / 2 \pi=20 \mathrm{kHz}$ was used; the recycle delay was $2 \mathrm{~s}$ and the crosspolarization contact time was $0.1 \mathrm{~ms}$. In both cases the $t_{1}$ evolution period consisted of 320 increments each made of 64 scans; the exchange period varied from 1 to $800 \mathrm{~ms}$; and the dipolar decoupling SPINAL 64 was applied during both detection periods. Spectral width in both dimensions was synchronized with the sample rotation $(20 \mathrm{kHz})$.

a)

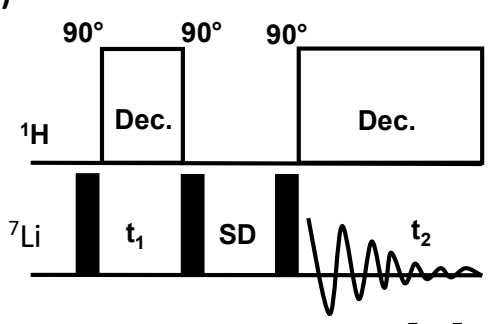

b)

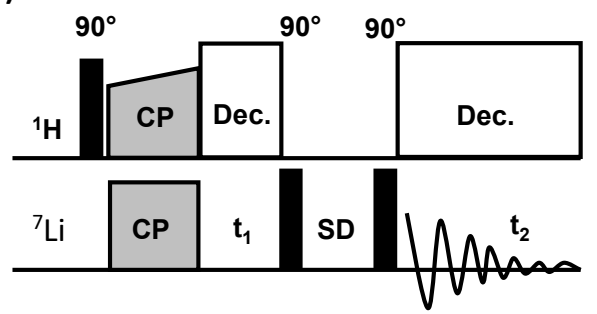

Figure S6. Schematic representations of $2 \mathrm{D}^{7} \mathrm{Li}-{ }^{7} \mathrm{Li}$ EXSY NMR experiments: a three-pulse NOESY-type experiment with direct excitation of ${ }^{7} \mathrm{Li}$ magnetization (a); and ${ }^{7} \mathrm{Li}-{ }^{7} \mathrm{Li}$ EXSY experiment employing ${ }^{1} \mathrm{H}-{ }^{7}$ li cross polarization (b).

${ }^{7} \mathrm{Li}-{ }^{7} \mathrm{Li} \mathrm{DQ} / \mathrm{SQ}$ MAS NMR correlation experiments: The $2 \mathrm{D}{ }^{7} \mathrm{Li}-{ }^{7} \mathrm{Li} \mathrm{DQ} / \mathrm{SQ}$ MAS NMR correlation spectra were measured using the ${ }^{7} \mathrm{Li}-{ }^{7} \mathrm{Li}$ double-quantum (DQ) experiment employing the $\mathrm{BR}^{1}{ }^{1}$ recoupling sequence at spinning frequency $\omega_{r} / 2 \pi=20 \mathrm{kHz}$ (Figure S7). The recycle delay was $4 \mathrm{~s}, t_{1}$ evolution period consisted of 256 increments each made of 240 scans. The DQ coherence excitation and reconversion consisted of 2-4 loops (duration of one loop was $200 \mu \mathrm{s}$ ). The dipolar decoupling SPINAL 64 was applied during both detection periods and LG-CW decoupling was used during the build-up of DQ coherence.

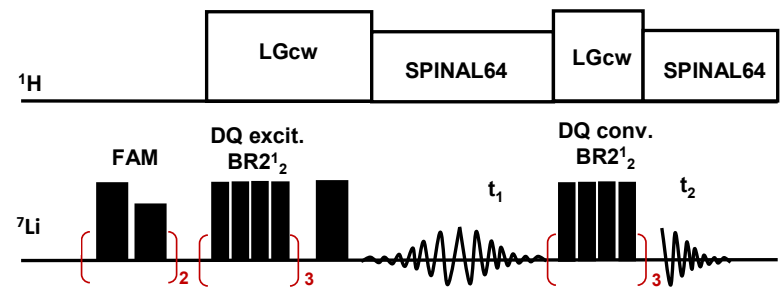

Figure S7. Representation of $2 \mathrm{D}^{7} \mathrm{Li}-{ }^{7} \mathrm{Li} \mathrm{DQ}-\mathrm{SQ}$ experiment with FAM excitation and $\mathrm{BR} 2{ }^{1}{ }_{2}$ recoupling sequence. 
${ }^{27}$ Al TQ/MAS NMR: The 2D triple-quantum (TQ) ${ }^{27} \mathrm{Al}$ TQ/MAS NMR spectra were measured using the three-pulse sequence with the excitation, reconversion and selective pulses of $4.2,1.5$ and $43 \mu$ s lengths, respectively. The reconversion and selective pulses were spaced by the $z$-filter of $20 \mu$ s length (Figure S8). The dipolar decoupling SPINAL 64 was applied during both detection periods.

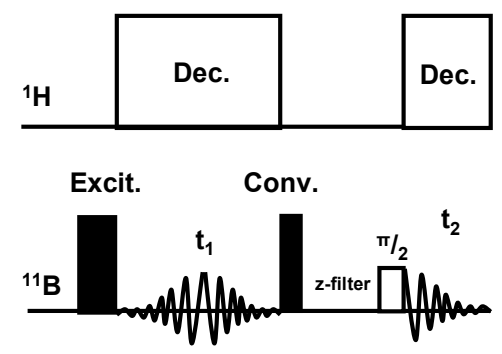

Figure S8. Schematic representation of $2 \mathrm{D}^{27} \mathrm{Al} T \mathrm{TQ} / \mathrm{MAS}$ NMR experiment.

Powder X-ray diffraction (PXRD) Powder X-ray diffraction (PXRD) data were collected on the powder diffractometer Empyrean of PANalytical, which was equipped by sealed Cu anode ( $\lambda_{\text {cuk } \alpha}=1.54184 \AA$ ), focusing mirror, capillary holder and PIXcel3D detector. The sample was ground and placed to the $0.5 \mathrm{~mm}$ borosilicateglass capillary. The Rietveld Refinement was done in the program Jana2006. All crystal structures were obtained from the CSD database, and their atomic coordinates were fixed during the refinement. Only unit cell parameters and profile were refined.

AC conductivity was measured by impedance spectroscopy using an Autolab PGSTAT12 equipped with a FRA2 module. The input capacitance and impedance of the instrument are lower than 8pF and higher than 100G $\Omega$, respectively. The measurements were carried out in potentiostatic mode (voltage amplitude $0.2 \mathrm{~V}$ ) over the frequency from $0.1 \mathrm{~Hz}$ to $1 \mathrm{MHz}$ at two different temperatures $(300 \mathrm{~K}, 373 \mathrm{~K})$ and two relative humidities $(25 \%$ and 75\%). The conductivity of sample $\sigma$ was calculated using relation $\sigma=t / R . A$, where $t$ and $A$ are the thickness and face area of sample, respectively, and $R$ is resistivity deduced from impedance data at zero-phase angel (the real part of complex impedance data).

\section{References:}

(2) Salager, E.; Stein, R. S.; Steuernagel, S.; Lesage, A.; Elena, B.; Emsley, L.; Enhanced sensitivity in highresolution ${ }^{1} \mathrm{H}$ solid-state NMR spectroscopy with DUMBO dipolar decoupling under ultra-fast MAS; Chem. Phys. Lett. 2009, 469, 336-341.

(3) Hong, M.; Yao, X.; Jakes, K.; Huster, D.; Investigation of Molecular Motions by Lee-Goldburg CrossPolarization NMR Spectroscopy; J. Phys. Chem. B 2002, 106, 7355-7364.

(4) Van Rossum, B.-J.; Förster, H.; De Groot, H.; High-Field and High-Speed CP-MAS ${ }^{13} \mathrm{C}$ NMR Heteronuclear Dipolar-Correlation Spectroscopy of Solids with Frequency-Switched Lee-Goldburg Homonuclear Decoupling; J. Magn. Reson. 1997, 124, 516-519.

(5) Szeverenyi, N. M.; Sullivan, M. J.; Maciel, G. E.; Observation Of Spin Exchange By Two-Dimensional Fourier-Transform C-13 Cross Polarization-Magic-Angle Spinning; J. Magn. Reson. 1982, 47, 462-475.

(6) Schnell, I.; Brown, S. P.; Low, H. Y.; Ishida, H.; Spiess, H. W.; An investigation of hydrogen bonding in benzoxazine dimers by fast magic-angle spinning and double-quantum H-1 NMR spectroscopy; J. Am. Chem. Soc. 1998, 120, 11784-11795

(7) Brown, S. P.; Spiess, H. W.; Advanced solid-state NMR methods for the elucidation of structure and dynamics of molecular, macromolecular, and supramolecular systems; Chem. Rev. 2001, 101, 4125-4156.

(8) Edén, M.; Zhou, D.; Yu, J.; Improved double-quantum NMR correlation spectroscopy of dipolar-coupled quadrupolar spins; Chem. Phys. Lett. 2006, 431, 397-403. 
(9) Wang, Q.; Hu, B.; Lafon, O.; Trébosc, J.; Deng, F.; Amoureux, J.; Double-quantum homonuclear NMR correlation spectroscopy of quadrupolar nuclei subjected to magic-angle spinning and high magnetic field; $J$. Magn. Reson. 2009, 200, 251-260

(10) Amoureux, J.-P.; Fernandez, C.; Steuernagel, S.; Z filtering in MQMAS NMR; J. Magn. Reson., Ser. A 1996, 123, 116-118.

(11) Langer, B.; Schnell, I.; Spiess, H. W.; Grimmer, A.-R.; Temperature calibration under ultrafast MAS conditions; J. Magn. Reson. 1999, 138, 182-186.

(12) Brus, J.; Heating of samples induced by fast magic-angle spinning; Solid State Nucl. Magn. Reson. 2000, $16,151-160$. 
Quantum chemical calculations: The plane wave density functional theory (PW DFT) based approach was applied in the pseudopotential scheme $\mathrm{e}^{13-15}$ as implemented in the CASTEP 16.1 code $^{15}$. The following two periodic structures were subjected to the simultaneous optimization of the unit cell parameters and of internal coordinates with respect to the crystal lattice energy approximated by the PBE exchange-correlation functional ${ }^{16}$ with the TS dispersion correction scheme ${ }^{17}$ :

1. The MIL53(Al)ht phase described in Table S5 of reference [18], and

2. The MIL53(AI)/t phase from reference [19].

For the resulting structures, PW DFT chemical shielding (CS) tensors were predicted using the gauge-including projector augmented wave (GIPAW) ${ }^{20,21}$ method combined with the PBE functional, and the isotropic CS shielding $(\sigma)$ is reported below. The PW DFT electric field gradient (EFG) tensors were predicted, also using the PBE functional, by the method described in reference [22] (the quadrupolar coupling constant $\left(\mathrm{C}_{\mathrm{Q}}\right)$ and the asymmetry parameter $\left(\eta_{\mathrm{Q}}\right)$ were obtained from the principal components of the EFG tensors). In all CASTEP calculations, the on-the-fly generated pseudopotentials were used with the inclusion of scalar relativistic effects through the ZORA method ${ }^{23}$, and the settings were consistent with 'Fine' accuracy level of the Materials Studio software ${ }^{24}$. The resulting approach is abbreviated as PBE-TS-ZORA. Estimates of the ${ }^{27} \mathrm{Al}$ chemical shift, $\delta^{\prime}$, were obtained from the PBE-TS-ZORA 27-Al $\sigma$ values according to the calibration provided in Figure S10 of refence [25]:

$\delta^{\prime}=-1.0005^{*} \sigma+556.51 \mathrm{ppm}$

The $\delta^{\prime}$ values are rounded to one ppm, as their uncertainty is several ppm (see the discussion of an older (alibration $)^{26}$.

Table S1a. The PBE-TS-ZORA ${ }^{27}$ Al NMR parameters of the open-pore thermally activated modification MIL53(Al)ht (shielding $\sigma$, quadrupolar coupling constant $C_{Q}$ and asymmetry parameter, $\eta_{Q}$ ).

\begin{tabular}{|c|c|c|c|c|}
\hline $\begin{array}{l}\text { MIL53(Al)ht } \\
\text { crystallographic } \\
\text { site }\end{array}$ & $\sigma($ in ppm) & $\delta^{\prime}$ (in ppm) & $\mathrm{C}_{\mathrm{Q}}($ in $\mathrm{MHz})$ & $\eta_{Q}$ (unitless) \\
\hline Al1 & 552.90 & 3 & 7.5 & 0.09 \\
\hline
\end{tabular}

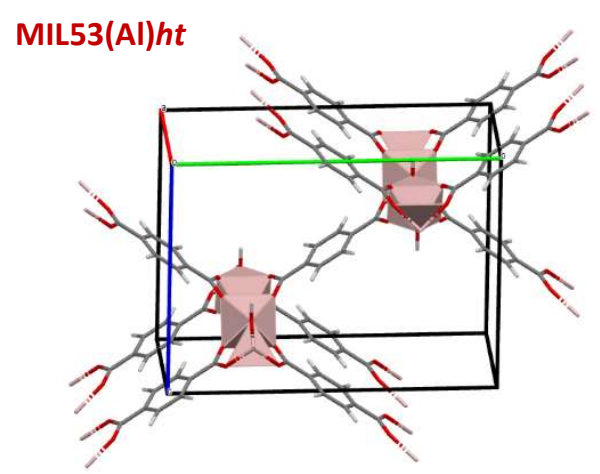


Table S1b. The PBE-TS-ZORA ${ }^{27}$ AI NMR parameters of the narrow-pore fully hydrated modification MIL53(AI)/t (shielding $\sigma$, quadrupolar coupling constant $C_{Q}$ and asymmetry parameter, $\eta_{Q}$ ).

\begin{tabular}{ccccc}
\hline $\begin{array}{c}\text { MIL53(Al)/t } \\
\text { crystallographic } \\
\text { site }\end{array}$ & $\sigma$ (in ppm) & $\delta^{\prime}$ (in ppm) & CQ (in MHz) & $\eta_{Q}$ (unitless) \\
\hline Al1 & 551.72 & 5 & 12.8 & 0.14 \\
Al2 & 551.42 & 5 & 13.3 & 0.27 \\
Al3 & 552.09 & 4 & 11.2 & 0.57 \\
\hline
\end{tabular}

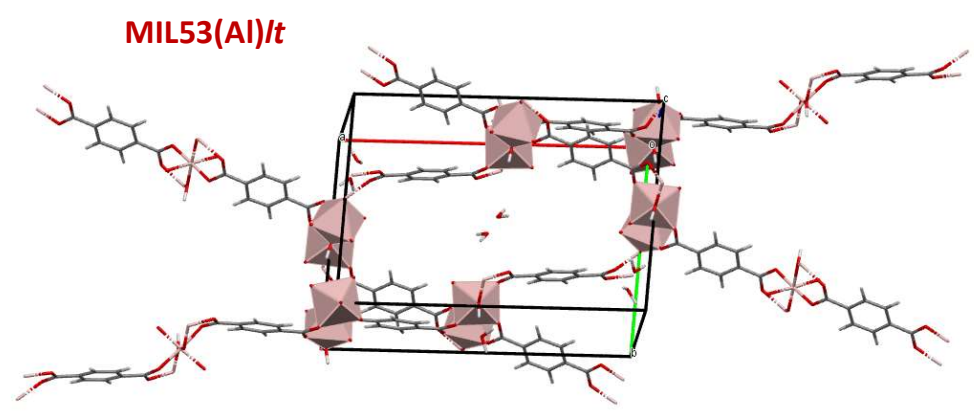

In addition, the computations were performed for the MIL53(Al)/t with the water molecules removed. As demonstrated in Table S1d the unit cell parameters slightly change by the water molecules removal, however, are not completely recovered to the open-pore thermally activated modification MIL53(Al)ht.

Table S1c. The PBE-TS-ZORA ${ }^{27}$ AI NMR parameters of the MIL53(AI)/t structure after removal of water molecules.

\begin{tabular}{|c|c|c|c|c|c|}
\hline $\begin{array}{c}\text { structural } \\
\text { optimization }\end{array}$ & $\begin{array}{l}\text { crystallographic } \\
\text { site }\end{array}$ & $\sigma($ in $p p m)$ & $\delta^{\prime}($ in $p p m)$ & $\mathrm{C}_{\mathrm{Q}}($ in $\mathrm{MHz})$ & $\eta_{\mathrm{Q}}$ (unitless) \\
\hline \multirow{3}{*}{ none } & Al1 & 553.02 & 3 & 11.0 & 0.14 \\
\hline & $\mathrm{Al} 2$ & 553.32 & 3 & 11.7 & 0.27 \\
\hline & $\mathrm{Al} 3$ & 553.87 & 2 & 9.4 & 0.58 \\
\hline \multirow{3}{*}{$\begin{array}{c}\text { of internal } \\
\text { coordinates only }\end{array}$} & Al1 & 553.64 & 3 & 9.0 & 0.21 \\
\hline & $\mathrm{Al} 2$ & 552.98 & 3 & 10.8 & 0.18 \\
\hline & $\mathrm{Al} 3$ & 554.17 & 2 & 7.5 & 0.14 \\
\hline \multirow{3}{*}{$\begin{array}{l}\text { of internal } \\
\text { coordinates and } \\
\text { the unit cell }\end{array}$} & Al1 & 555.28 & 1 & 7.6 & 0.15 \\
\hline & $\mathrm{Al} 2$ & 555.14 & 1 & 8.6 & 0.19 \\
\hline & $\mathrm{Al} 3$ & 555.62 & 1 & 6.7 & 0.12 \\
\hline
\end{tabular}

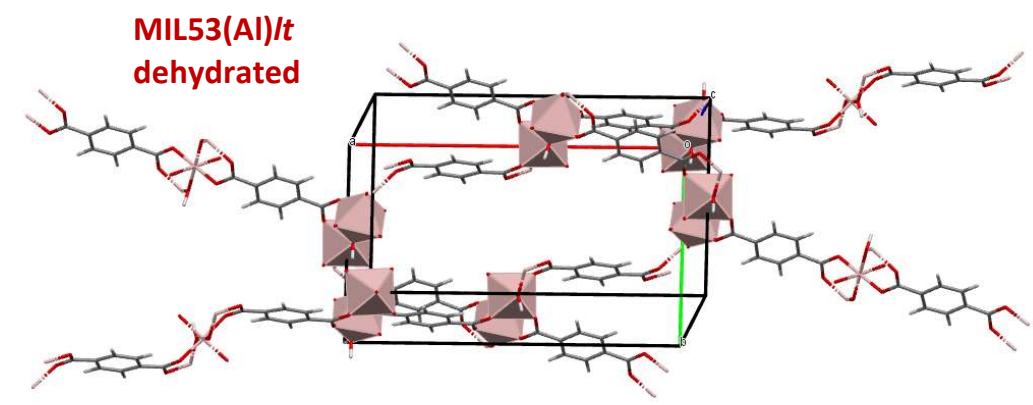


Table S1d. The parameters of the PBE-TS-ZORA optimized unit cells ( $\alpha=\gamma=90^{\circ}$ in all three cases).

\begin{tabular}{ccccccc}
\hline system & $\begin{array}{c}\text { space } \\
\text { group }\end{array}$ & $a$ (in $\AA)$ & $b$ (in $\AA)$ & $c$ (in $\AA$ ) & $\beta\left(\right.$ in $\left.{ }^{\circ}\right)$ & volume (in $\left.\AA^{3}\right)$ \\
\hline MIL53(Al)ht & $\begin{array}{l}\text { Imma } \\
(\# 74)\end{array}$ & 6.7032 & 16.8783 & 12.8463 & 90.00 & 1453 \\
MIL53(AI)/t & $\begin{array}{r}P 21 / c \\
(\# 14)\end{array}$ & 19.5499 & 14.7138 & 6.5783 & 103.81 & 1838 \\
$\begin{array}{l}\text { MIL53(AI)/t } \\
\text { w/o water }\end{array}$ & $\begin{array}{l}P 2_{1} / c \\
(\# 14)\end{array}$ & 19.7386 & 13.0860 & 6.6498 & 104.11 & 1666 \\
\hline
\end{tabular}

\section{References:}

(13) Kresse G; Joubert D.; From ultrasoft pseudopotentials to the projector augmented-wave method; Phys. Rev. B. 1999, 59, (3), 1758-1775.

(14) Segall, M.D.; Lindan, P.J.D.; Probert, M.J.; Pickard, C.J.; Hasnip, P.J.; Clark, S.J.; Payne, M.C.; First-principles simulation: ideas, illustrations and the CASTEP code; J. Phys. Condens. Matter. 2002, 14, (11), 2717-2744.

(15) Clark, S. J.; Segall, M. D.; Pickard, C. J.; Hasnip, P. J.; Probert, M. J.; Refson, K.; Payne, M. C.; First principles methods using CASTEP; Zeitschrift Fur Kristallographie 2005, 220, (5-6), 567-570.

(16) Perdew, J. P.; Burke, K.; Ernzerhof, M.; Generalized gradient approximation made simple; Phys. Rev. Lett. 1996, 77, (18), 3865-3868.

(17) Tkatchenko, A.; Scheffler, M.; Accurate Molecular Van Der Waals Interactions from Ground-State Electron Density and Free-Atom Reference Data; Phys. Rev. Lett. 2009, 102, (7), 4.

(18) Liu, Y.; Her, J. H.; Dailly, A.; Ramirez-Cuesta, A. J.; Neumann, D. A.; Brown, C. M.; Reversible structural transition in MIL-53 with large temperature hysteresis; J. Am. Chem. Soc. 2008, 130, 11813-11818.

(19) Ortiz, G.; Chaplais, G.; Paillaud, J. L.; Nouali, H.; Patarin, J.; Raya, J.; Marichal, C.; New Insights into the Hydrogen Bond Network in Al-MIL-53 and Ga-MIL-53; J. Phys. Chem. C 2014, 118, 22021-22029.

(20) Pickard, C. J.; Mauri, F. "All-electron magnetic response with pseudopotentials: NMR chemical shifts", Phys. Rev. B. 2001, 63, (24), 13.

(21) Yates, J. R.; Pickard, C. J.; Mauri, F. "Calculation of NMR chemical shifts for extended systems using ultrasoft pseudopotentials", Phys. Rev. B. 2007, 76, (2), 024401.

(22) Profeta, M.; Mauri, F.; Pickard, C. J. "Accurate First Principles Prediction of 170 NMR Parameters in SiO2: Assignment of the Zeolite Ferrierite Spectrum", J. Am. Chem. Soc. 2003, 125, (2) 541-548.

(23) Yates, J. R.; Pickard, C. J.; Payne, M. C.; Mauri, F. "Relativistic nuclear magnetic resonance chemical shifts of heavy nuclei with pseudopotentials and the zeroth-order regular approximation", J. Chem. Phys. 2003, 118, (13), 5746-5753.

(24) https://www.3dsbiovia.com/products/collaborative-science/biovia-materials-studio/

(25) Karasulu, B.; Emge, S. P.; Groh, M. F.; Grey, C. P.; Morris, A. J. “Al/Ga-Doped Li7La3Zr2O12 Garnets as LiIon Solid-State Battery Electrolytes: Atomistic Insights into Local Coordination Environments and Their Influence on 170, 27Al, and 71Ga NMR Spectra", J. Am. Chem. Soc. 2020, 142, (6) 3132-3148.

(26) Middlemiss, D. S.; Blanc, F.; Pickard, C. J.; Grey, C. P. "Solid-state NMR calculations for metal oxides and gallates: Shielding and quadrupolar parameters for perovskites and related phases", J. Magn. Reson. 2010, 204, 1-10. 


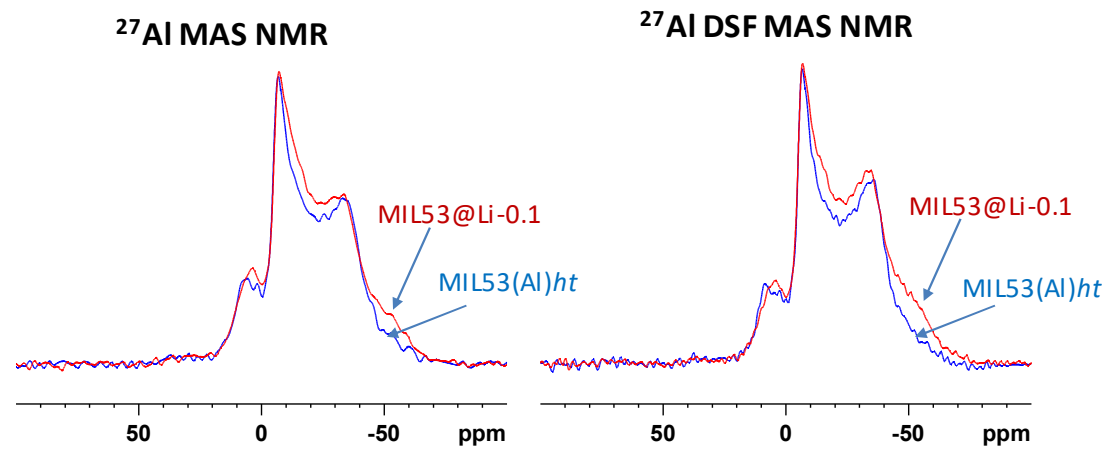

Figure S9. ${ }^{27} \mathrm{Al}$ MAS and DSF/MAS NMR spectra of the thermally activated parent modification MIL53(Al)ht (blue lines); and the host-guest composite MIL53(Al)@LiCoD-0.10 (red lines).

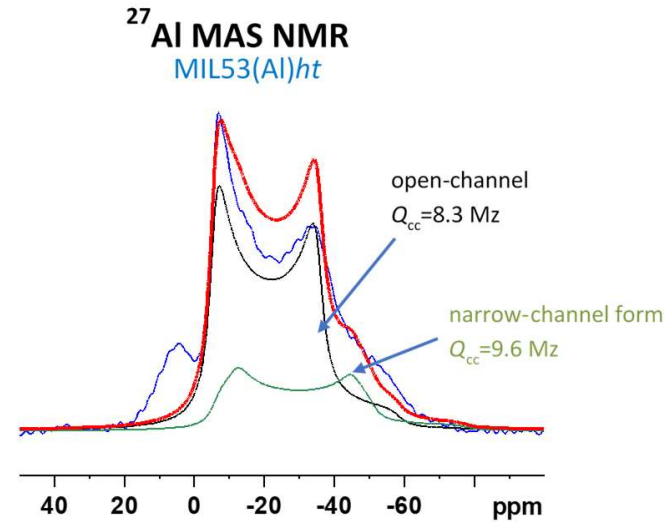

Figure S10. ${ }^{27} \mathrm{AI}$ MAS NMR spectrum of the thermally activated parent modification MIL53(AI)ht (blue line); and decomposition on individual spectral components reflecting open-pore and narrow-pore modifications.

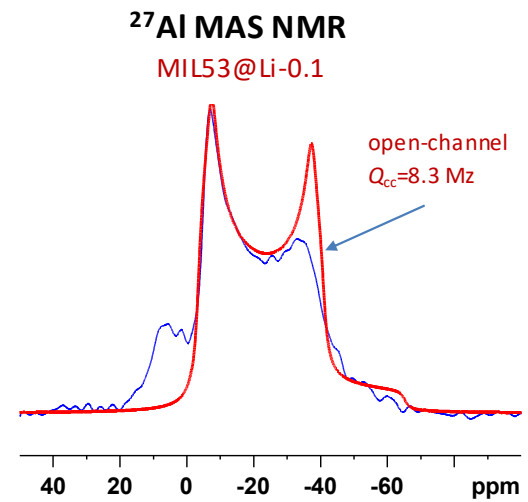

Figure S11. ${ }^{27} \mathrm{Al}$ MAS NMR spectrum of the host-guest composite MIL53(Al)@LiCoD-0.10 (blue line); and the lineshape simulation for the open-pore modification. 
Segmental dynamics. It has long been recognized, that besides the structure, also molecular dynamics covering a wide range of time-scales, from picoseconds to seconds, determine end-use properties of materials. The dynamics of individual segments, function groups or building blocks exhibiting varying amplitudes and geometries, such as small-amplitude librations, aromatic ring flips or aliphatic side-chains jumps, can be characterized by an order parameter $S^{2}$ (Eqs. 1-3) and a correlation time $\tau$. In general, the order parameter $S^{2}$ is a measure of the equilibrium distribution of orientations of the bond vector $\mu(\mathrm{t})$ in a molecular reference frame and ranges from 1 for fixed orientation to 0 for free motion. ${ }^{27}$ In the simplest case, assuming a small-amplitude $\langle\theta\rangle$ axially-symmetric motion (so that $\langle\sin \theta\rangle \approx\langle\theta\rangle$ ), the order parameter can be converted ${ }^{27,29,30}$ to the average fluctuation angle $\sqrt{\left\langle\theta^{2}\right\rangle}$ :

$$
S^{2}=1-\frac{3}{2}\left\langle\theta^{2}\right\rangle
$$

For complicated motions other models providing more instructive pictures can be applied. For instance, rapid jumps of the bond vector between $N$ distinct orientations with populations $p_{i}$ are analyzed according to the following relation ${ }^{27,30}$ :

$$
S^{2}=\sum_{i, j=1}^{N} p_{i} p_{j} P_{2}\left(\cos \theta_{i j}\right)
$$

If the motion is modeled by the Gaussian axial fluctuation model ${ }^{31}$ the bond vector diffuses within a parabolic potential on the surface of a cone:

$$
S^{2}=1-3 \sin ^{2} \theta\left\{\left[\cos ^{2} \theta\left(1-\exp \left[-\sigma_{f}^{2}\right]\right)+0.25 \sin ^{2} \theta\left(1-\exp \left[-4 \sigma_{f}^{2}\right]\right)\right\}\right.
$$

where $\theta$ is the (fixed) angle between the bond vector $\mu(\mathrm{t})$ and the director axis for the motion and $\sigma$ is the standard deviation of the fluctuation in the azimuthal angle.

Order parameter and ${ }^{1} \mathrm{H}-{ }^{13} \mathrm{C}$ one-bond dipolar couplings. The ${ }^{1} \mathrm{H}-{ }^{13} \mathrm{C}$ separated-local-filed experiments (PILGRIM $^{32}$, AM-PISEMA ${ }^{33}$ ) make straightforward the site-specific measurements of dipolar couplings, which contain information about the motional amplitudes of molecular segments. This is allowed by the fact, that any molecular motion with a correlation time shorter than ca. $40 \mu$ s causes averaging of one-bond ${ }^{13} \mathrm{C}-{ }^{1} \mathrm{H}$ dipolar interactions (ca. $\omega_{\mathrm{D}} / 2 \pi=23.7 \mathrm{kHz}$ ). Then the ratio of a motionally averaged dipolar coupling constant $\left(D_{\mathrm{CH}}\right)$ and the rigid-limit value $\left(D_{\mathrm{CH}, \text { rig }}\right)$ defines an order parameter $\left(S^{2}\right)$ that can be converted to the amplitude of segmental motion $^{27}$ (Eq. 1-3). Following from the experimental Lee-Goldburg condition ${ }^{34}$, the scaling factor $\cos \left(54.7^{\circ}\right)$ reduces the rigid-limit value of a typical one-bond $\mathrm{C}-\mathrm{H}$ pair to be ca. $13.6 \mathrm{kHz}$. The order parameters were estimated from the dipolar profiles of $\mathrm{CH}$ groups since the dominant splittings observed in the dipolar spectra reflect spin-pair one-bond ${ }^{13} \mathrm{C}-{ }^{1} \mathrm{H}$ dipolar couplings as confirmed by the previous spectral simulations ${ }^{28}$.

Variable-temperature ${ }^{1} \mathrm{H}-{ }^{13} \mathrm{C}$ one-bond dipolar couplings of MIL53(Al)@LiCoD-0.30 composite. The 2D and ${ }^{1} \mathrm{H}$ ${ }^{13}$ C SLF NMR spectra of MIL53(Al)@LiCoD-0.30 composite were measured at 297 and $325 \mathrm{~K}$. Subsequently, the

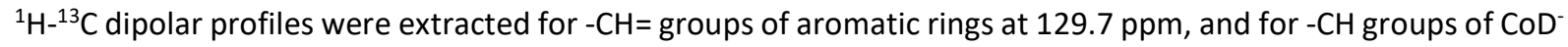
clusters at $50.6 \mathrm{ppm}$. The dipolar couplings displayed in Figures S12 were calculated from the determined splitting using the scaling factor $\cos \left(54.7^{\circ}\right)$. The order parameters $S^{2}$ were calculated as the ratio of a motionally averaged dipolar coupling constant $\left(D_{\mathrm{CH}}\right)$ and the rigid-limit value $\left(D_{\mathrm{CH} \text {,rig }}=23.7 \mathrm{kHz}\right)$. Using Equation 1 the determined order parameters were converted to the amplitude of segmental motion - average angular fluctuation angles $\langle\theta\rangle$.

Notice that fluctuation of aromatic segments is strongly temperature-dependent, whereas fluctuation and reorientation of $\mathrm{CoD}^{-}$ions is almost unaffected be temperature increase. 


\section{${ }^{1} \mathrm{H}-{ }^{13} \mathrm{C}$ SLF MAS NMR}

$-\mathrm{CH}=$ aromatic unit at

$129.7 \mathrm{ppm}$
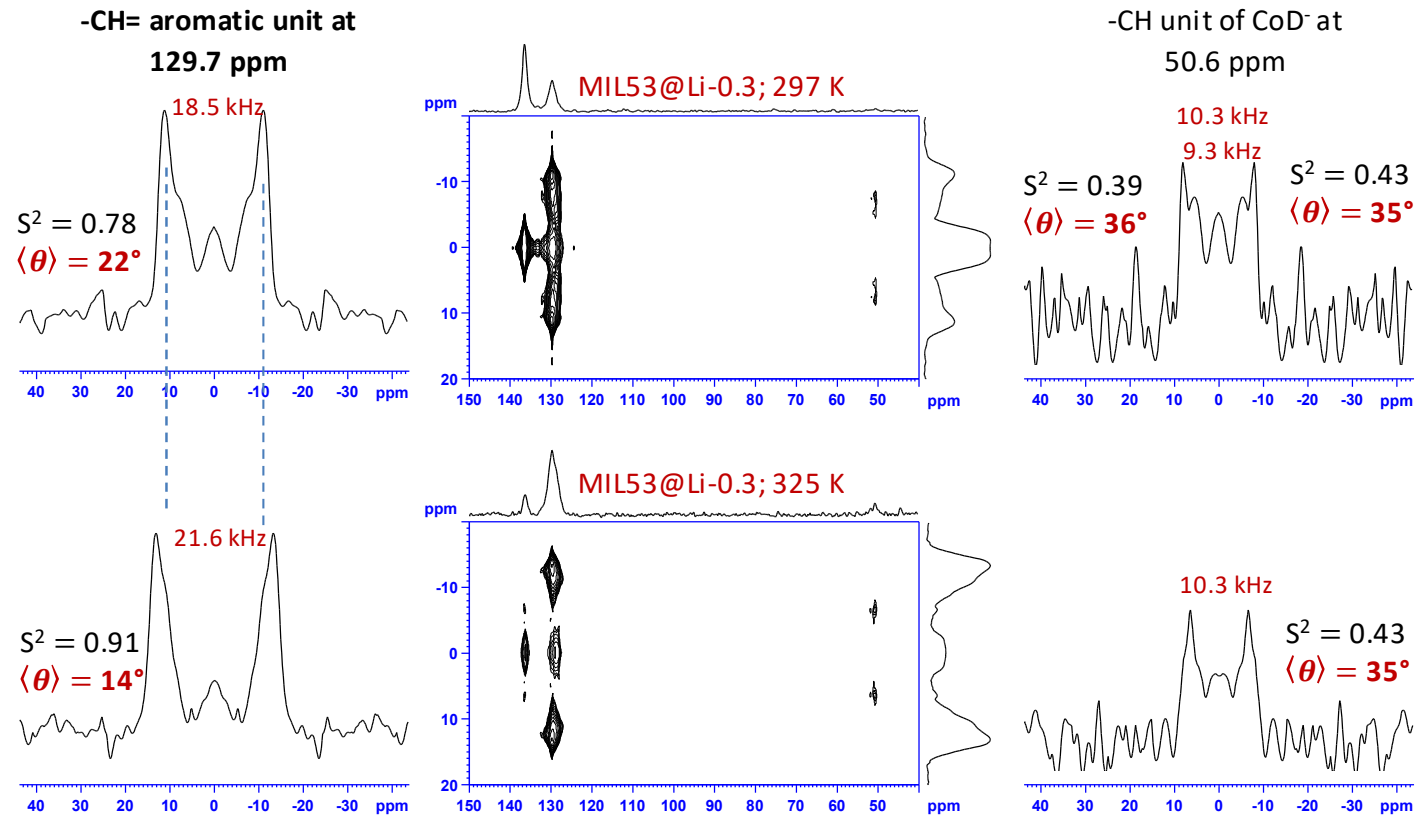

Figure S12a. The 2D ${ }^{1} \mathrm{H}_{-}{ }^{13} \mathrm{C}$ SLF MAS NMR spectra measured at 297 and $325 \mathrm{~K}$, and the ${ }^{1} \mathrm{H}-{ }^{13} \mathrm{C}$ dipolar profiles of $=\mathrm{CH}(\mathrm{Ar})$ and $-\mathrm{CH}\left(\mathrm{CoD}^{-}\right)$segments extracted for the MIL53(Al)@LiCoD-0.30 host-guest composite. The displayed dipolar couplings were calculated from the determined splitting using the scaling factor $\cos \left(54.7^{\circ}\right)$. The rigid-limit value of a typical one-bond $\mathrm{C}-\mathrm{H}$ pair is ca. $23.7 \mathrm{kHz}$. The average fluctuation angles were calculated according Equation 1.

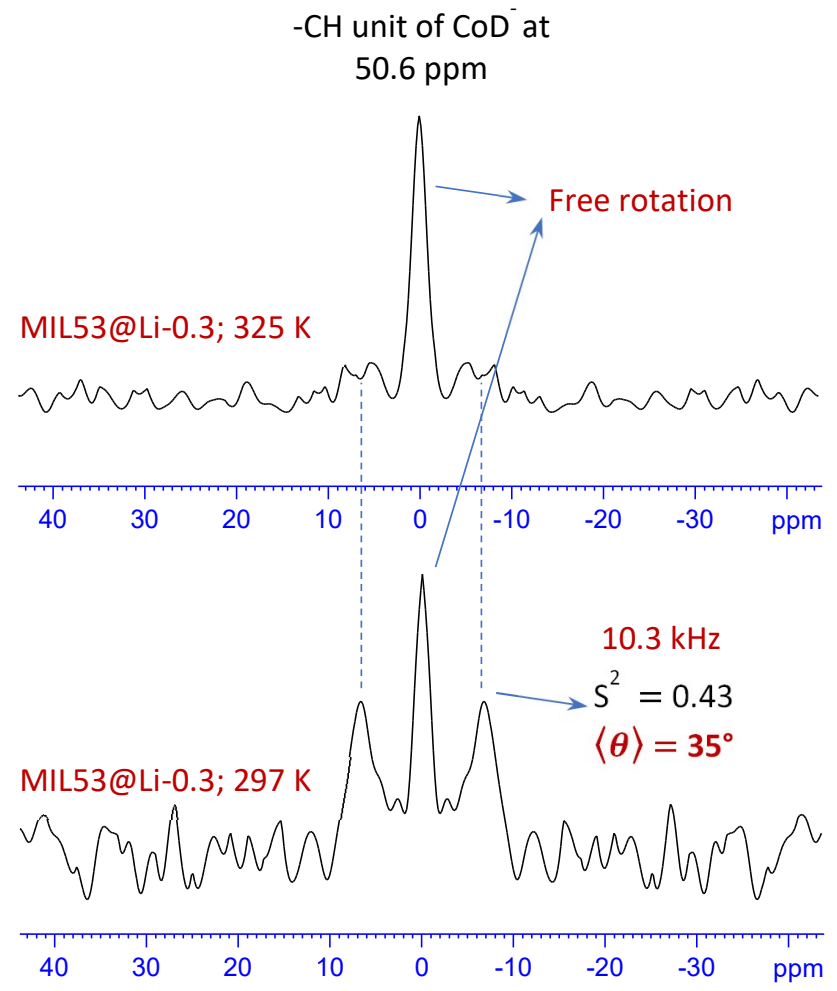

Figure S12b. The ${ }^{1} \mathrm{H}-^{13} \mathrm{C}$ dipolar profiles of $-\mathrm{CH}\left(\mathrm{COD}^{-}\right)$segments extracted for the MIL53(Al)@LiCoD-0.30 hostguest composite. The profiles specifically display the significant increase in the intensity of central resonances, which reflect (among others) weak dipolar couplings of rapidly (freely) rotating CoD guests. 


\section{References:}

(27) Palmer, A.G.; Williams, J.; McDermott, A. "Nuclear magnetic resonance studies of biopolymer dynamics", J. Phys. Chem. 1996, 100, 13293.

(28) Brus, J.; Jakeš, J. "Geometry of multiple-spin systems as reflected in $13 \mathrm{C}-\{1 \mathrm{H}\}$ dipolar spectra measured at Lee-Goldburg cross-polarization", Solid-State Nucl. Magn. Reson. 2005, 27, 180.

(29) Huster, D.; Xiao, L.S.; Hong, M. "Solid-State NMR Investigation of the Dynamics of the Soluble and Membrane-Bound Colicin la Channel-Forming Domain", Biochemistry 2001, 40, 7662.

(30) Lipari, G.; Szabo, A. "Model-free approach to the interpretation of nuclear magnetic resonance relaxation in macromolecules. 1. Theory and range of validity", J. Am. Chem. Soc. 1982, 104, 4546.

(31) Brüschweiler, R.; Wright, P.E. "NMR order parameters of biomolecules: a new analytical representation and application to the Gaussian axial fluctuation model", J. Am. Chem. Soc. 1994, 116, 8426.

(32) Hong, M.; Yao, X.; Jakes, K.; D. Huster, "Investigation of Molecular Motions by Lee-Goldburg CrossPolarization NMR Spectroscopy", J. Phys. Chem. B 2002, 106, 7355.

(33) Dvinskikh, S.V.; Zimmermann, H.; Maliniak, A.; Sandström, D., "Heteronuclear dipolar recoupling in liquid crystals and solids by PISEMA-type pulse sequences", J. Magn. Reson. 2003, 164, 165.

(34) Lee, M.; Goldburg, W. "Nuclear-Magnetic-Resonance Line Narrowing by a Rotating rf Field", Phys. Rev. 1965, 140, A1261. 


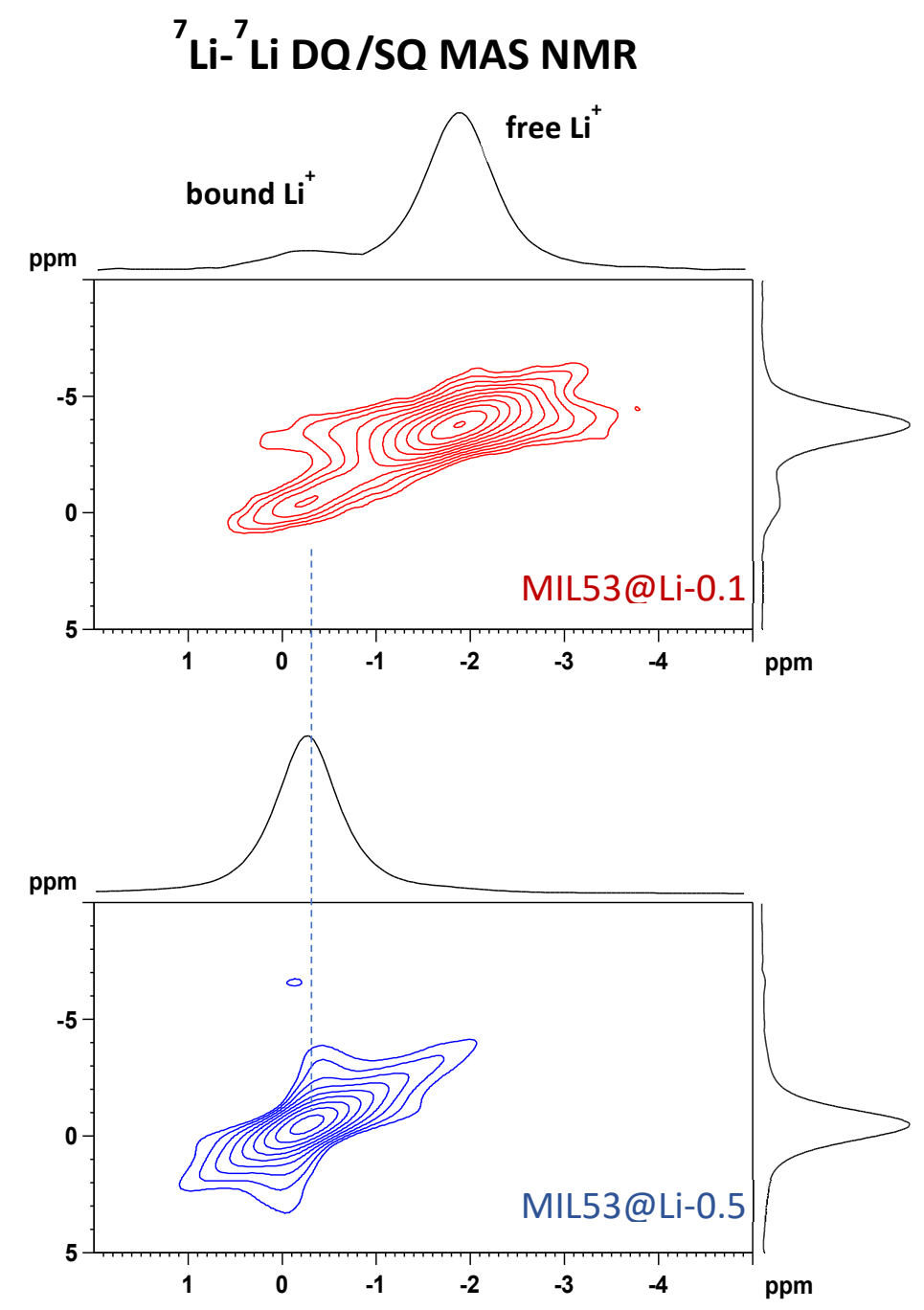

Figure S13. The 2D ${ }^{7} \mathrm{Li}^{-}{ }^{7} \mathrm{Li} \mathrm{DQ} / \mathrm{SQ}$ MAS NMR spectra measured MIL53(AI)@LiCoD-0.10 and MIL53(AI)@LiCoD-0.50 host-guest composites. 
Supporting Information S7 - ${ }^{7} \mathrm{Li}-{ }^{7} \mathrm{Li} \mathrm{DQ}$ coherence build-ups and ${ }^{7} \mathrm{Li}-{ }^{7} \mathrm{Li}$ interatomic distances

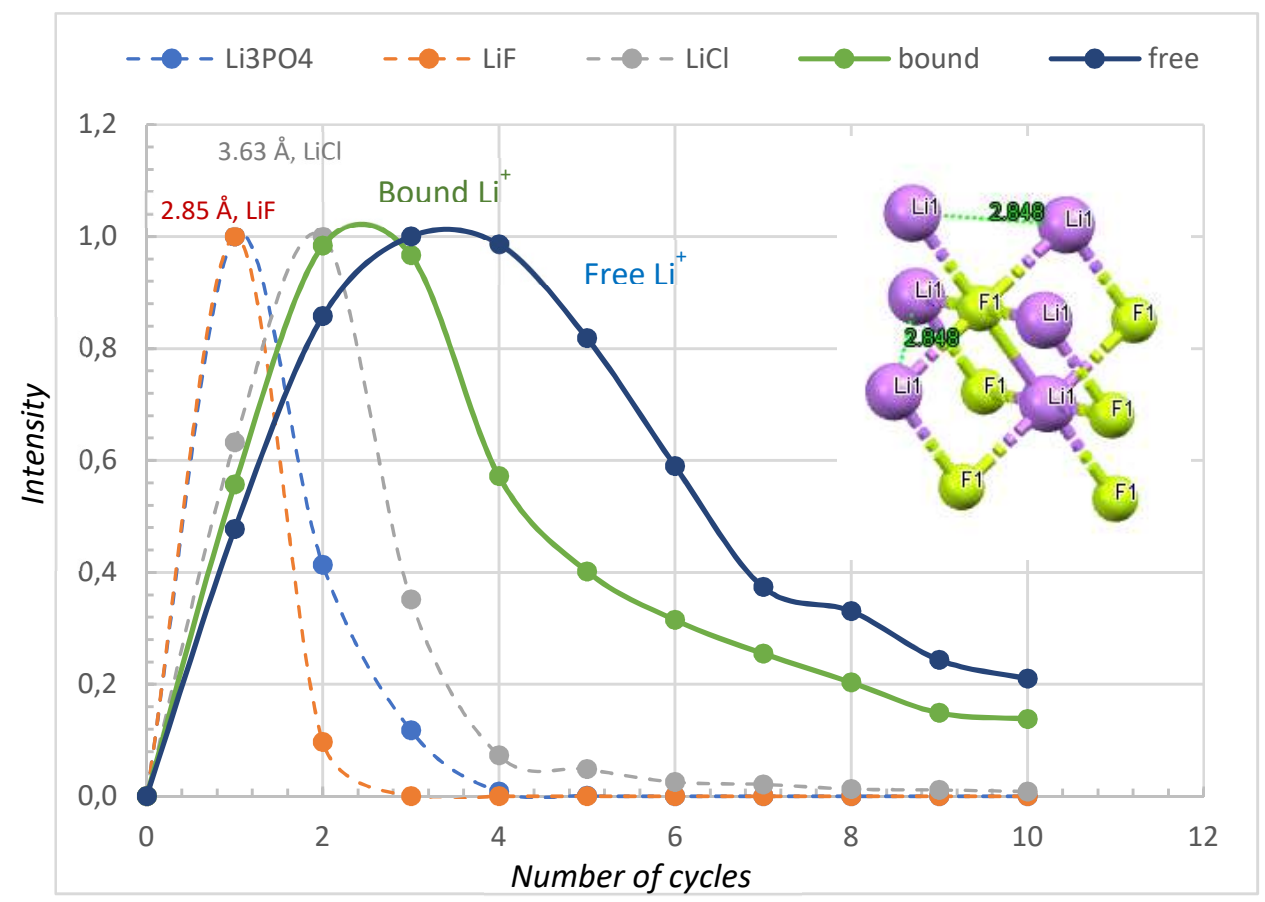

Figure S14. ${ }^{7} \mathrm{Li}-{ }^{7} \mathrm{Li} \mathrm{DQ}$ coherence build-ups recorded for $\mathrm{Li}_{3} \mathrm{PO}_{4}, \mathrm{LiF}, \mathrm{LiCl}$ and MIL53(Al)@LiCoD-0.10 bound and free $\mathrm{Li}^{+}$ions. Crystalline $\mathrm{Li}_{3} \mathrm{PO}_{4}, \mathrm{LiF}$, and $\mathrm{LiCl}$ represent the systems for which the ${ }^{7} \mathrm{Li}-{ }^{7} \mathrm{Li}$ distances are known from $x$-ray structures (for instance, in the inset see the structure of LiF).

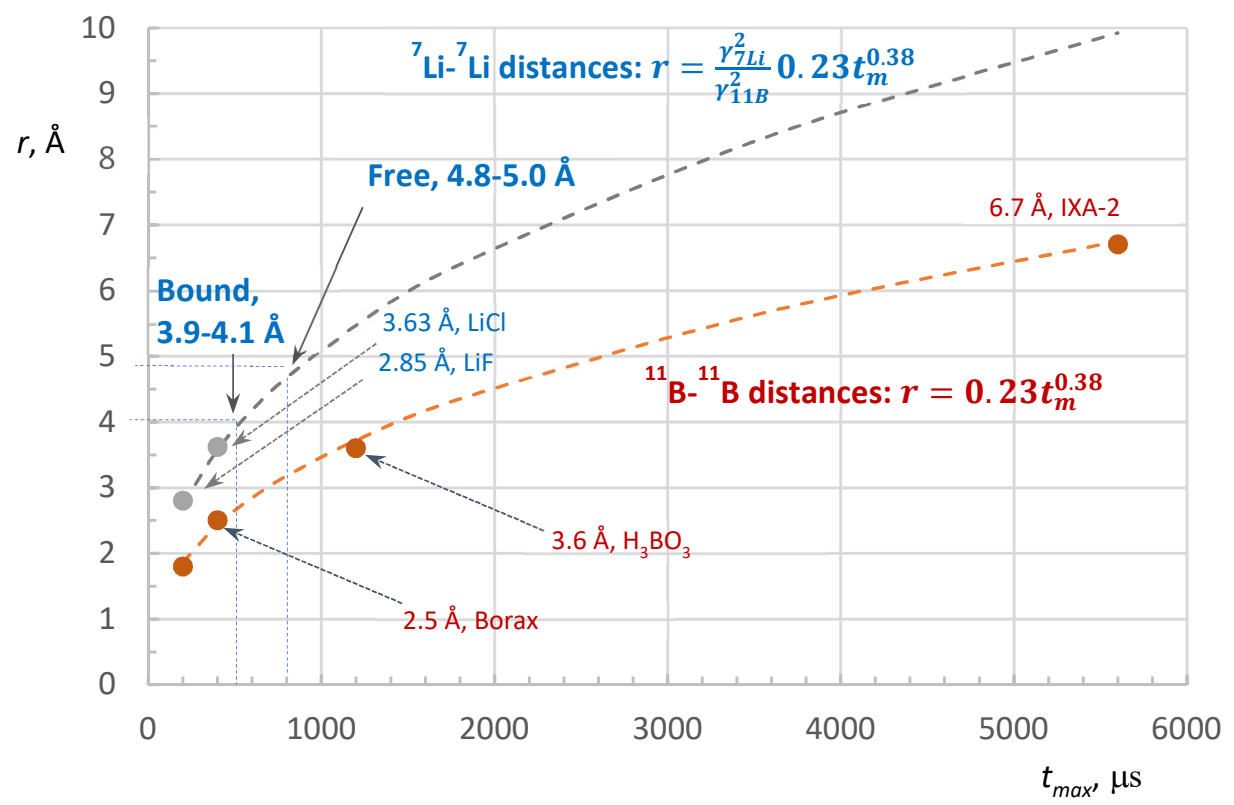

Figure S15. The previously experimentally determined dependence between the recoupling time at which maximum DQ coherence intensity is reached and the interatomic ${ }^{11} \mathrm{~B} . .{ }^{11} \mathrm{~B}$ distance (red line). This dependence

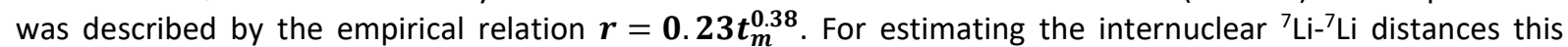
relation was simple re-parametrized by multiplying the constant by a factor $\left(\gamma_{\mathrm{LL}}\right)^{2} /\left(\gamma_{11 \mathrm{~B}}\right)^{2}$ (green line). The obtained relation $r=\frac{\gamma_{7 L i}^{2}}{\gamma_{11 B}^{2}} \mathbf{0 . 2 3 t _ { m } ^ { 0 . 3 8 }}$ was verified by using the ${ }^{7} \mathrm{Li}-{ }^{7} \mathrm{Li}$ distances independently obtained from $\mathrm{x}$ - 
ray structures of $\mathrm{LiF}$ and $\mathrm{LiCl}$. Subsequently this relation was used to estimate average internuclear ${ }^{7} \mathrm{Li}{ }^{7} \mathrm{Li}$ distances in pairs or chains formed by free $\mathrm{Li}^{+}$ions and by bound $\mathrm{Li}^{+}$ions.

To estimate distribution of $\mathrm{Li}^{+}$ions in more detail the inter-ionic distances were determined by analyzing the rate of evolution of ${ }^{7} \mathrm{Li}{ }^{7} \mathrm{Li} \mathrm{DQ}$ signals (Figure S14). By using the reference compounds with known $\mathrm{x}$-ray structure ( $\mathrm{Li}_{3} \mathrm{PO}^{4}$ with Li-Li distance of $2.97 \AA$; LiCl with Li-Li distance of $3.63 \AA$; and LiF with Li-Li distance of $2.85 \AA$ ), the previously derived relation $\left(r=\mathrm{A}_{11 \mathrm{~B}-11 \mathrm{~B} .} t_{\mathrm{m}}{ }^{0.38} ; \mathrm{A}_{11 \mathrm{~B}-11 \mathrm{~B}}=0.23\right)$ used for determining the ${ }^{11} \mathrm{~B} . . .{ }^{11} \mathrm{~B}$ interatomic distance $(r)$ from the recoupling time $\left(t_{\mathrm{m}}\right)$ was recalibrated for ${ }^{7} \mathrm{Li}$ nuclei (Figure S15). ${ }^{35}$ By using the new value of the

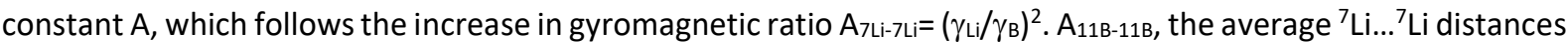
between free $\mathrm{Li}^{+}$is ca. $5.0 \pm 0.4 \AA$ and larger, whereas between the bound ions is shorter being in the range 3.0 to 4.0 A. As no detectable correlation signals between free and bound $\mathrm{Li}^{+}$ions were detected even by using the recoupling times longer than $2.4 \mathrm{~ms}$, the free and bound $\mathrm{Li}^{+}$species are separated by the average distance longer than ca. $7 \AA$.

\section{References:}

(35) Michal Hušák, Alexandr Jegorov, Jan Rohlíček, Andrew Fitch, Jiří Czernek, Libor Kobera, and Jiří Brus Determining the Crystal Structures of Peptide Analogs of Boronic Acid in the Absence of Single Crystals: Intricate Motifs of Ixazomib Citrate Revealed by XRPD Guided by ss-NMR, Crystal Growth \& Design 2018 18 (6), 3616-3625. DOI: 10.1021/acs.cgd.8b00402 


\section{${ }^{7}$ Li- ${ }^{7} \mathrm{Li}$ CP/MAS EXSY NMR}
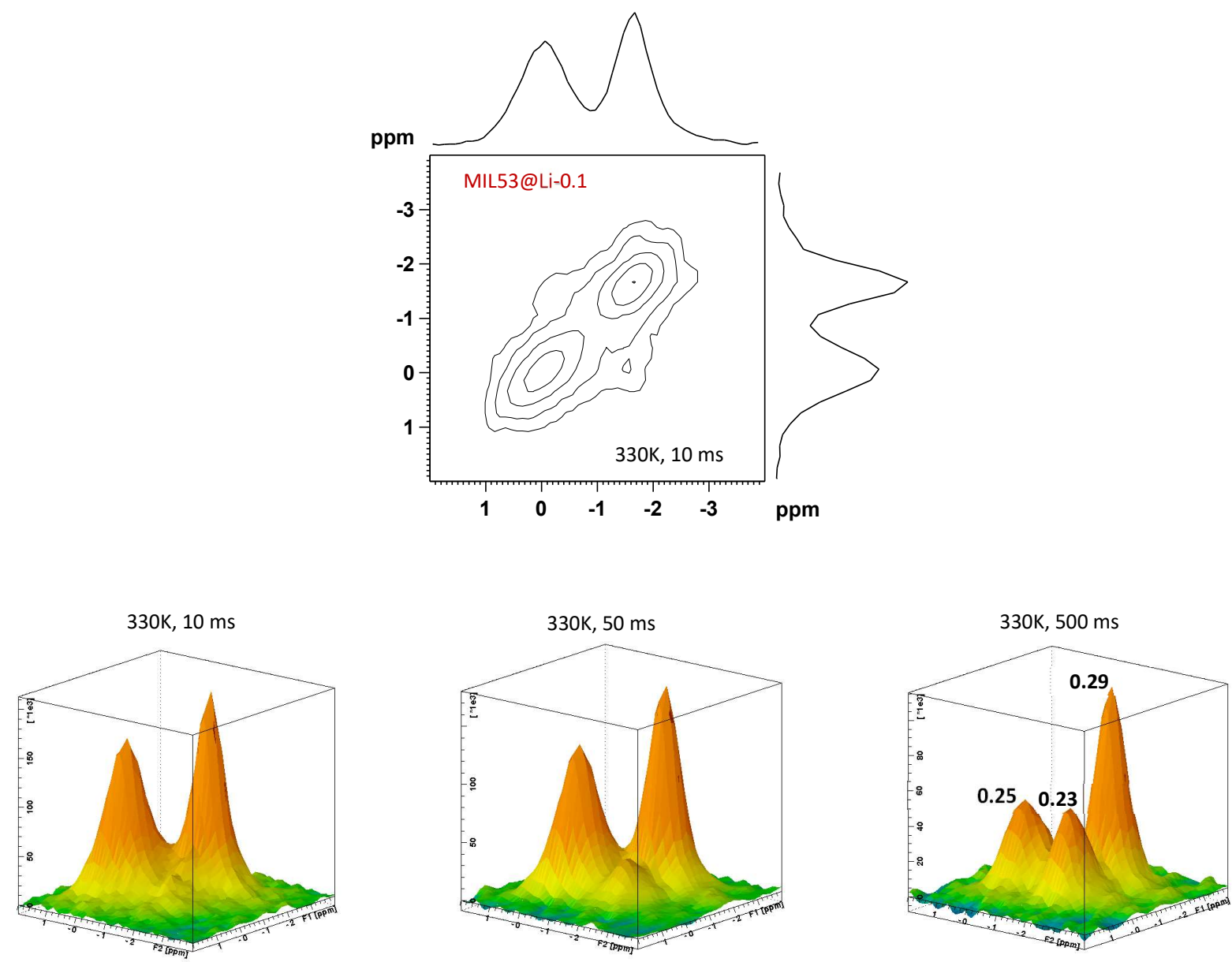

Figure S16. ${ }^{7} \mathrm{Li}-{ }^{7} \mathrm{Li}$ CP/MAS EXSY NMR spectra of MIL53(AI)@LiCoD-0.10 measured at $330 \mathrm{~K}$ and variable mixing time $(10,50$ and $500 \mathrm{~ms})$. Relative intensities of the cross-peak and diagonal signals are displayed for the spectrum measured at $500 \mathrm{~ms}$ mixing time. The relative intensities of diagonal signals determined at 0 mixing time for bound and free $\mathrm{Li}^{+}$ions are $l_{\mathrm{b}, \mathrm{b}}=0.52$ and $l_{\mathrm{f}, \mathrm{f}}=0.48$, respectively. Theoretical relative intensities of the cross-peaks at equilibrium can be calculated according to a relation, ${ }^{36} I_{e}=I_{b, f}=\frac{I_{b, b}^{0} I_{f, f}^{0}}{\sum_{i} I_{i}^{0}}$, where $I_{b, b}^{0}, I_{f, f}^{0}$ denote the intensity of diagonal signals measured at zero mixing time. The theoretical value calculated using this relation is $l_{b, f}=0.25$, whereas the experimentally determined value is $l_{b, f}=0.23$. This indicates that the chemical exchange nearly reached equilibrium at $500 \mathrm{~ms}$, and entire sources of $\mathrm{Li}^{+}$ions mutually communicate by the chemical exchange process.

\section{References:}

(36) Caravatti, P.; Neuenschwander, P.; Ernst, R. R. Characterization of Heterogeneous Polymer Blends by Two-Dimensional Proton Spin Diffusion Spectroscopy. Macromolecules 1985, 18, 119-122. 


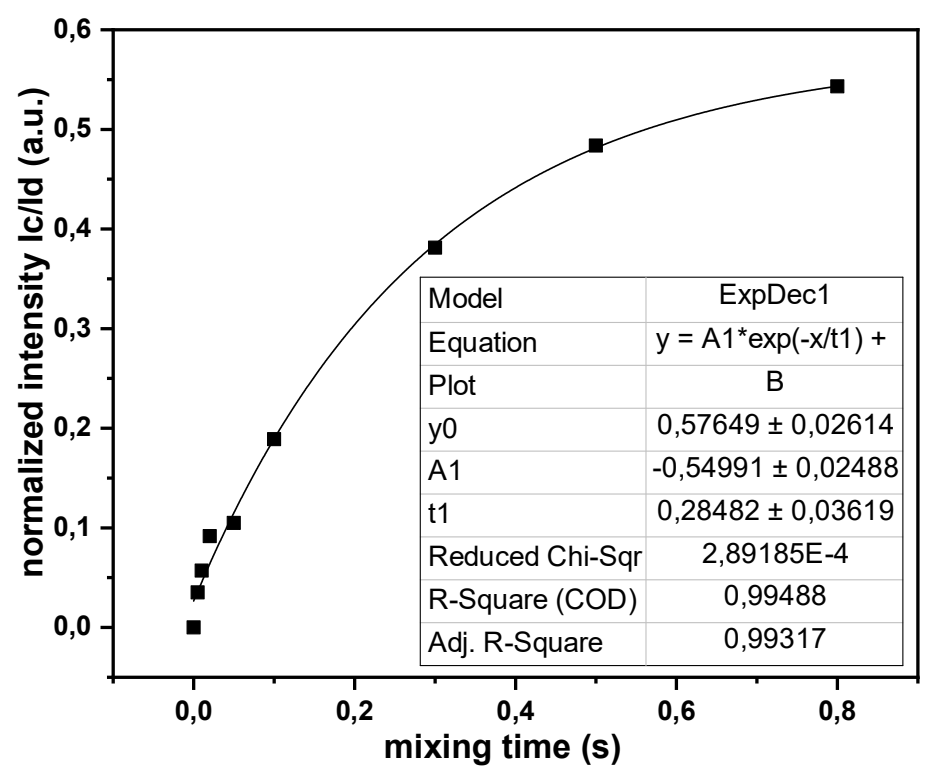

Figure S17. The ${ }^{7} \mathrm{Li}-{ }^{7} \mathrm{Li}$ chemical-exchange build-up curve determined from ${ }^{7} \mathrm{Li}-{ }^{7} \mathrm{Li}$ MAS EXSY NMR spectra of MIL53(AI)@LiCoD-0.10 measured at 295 K.

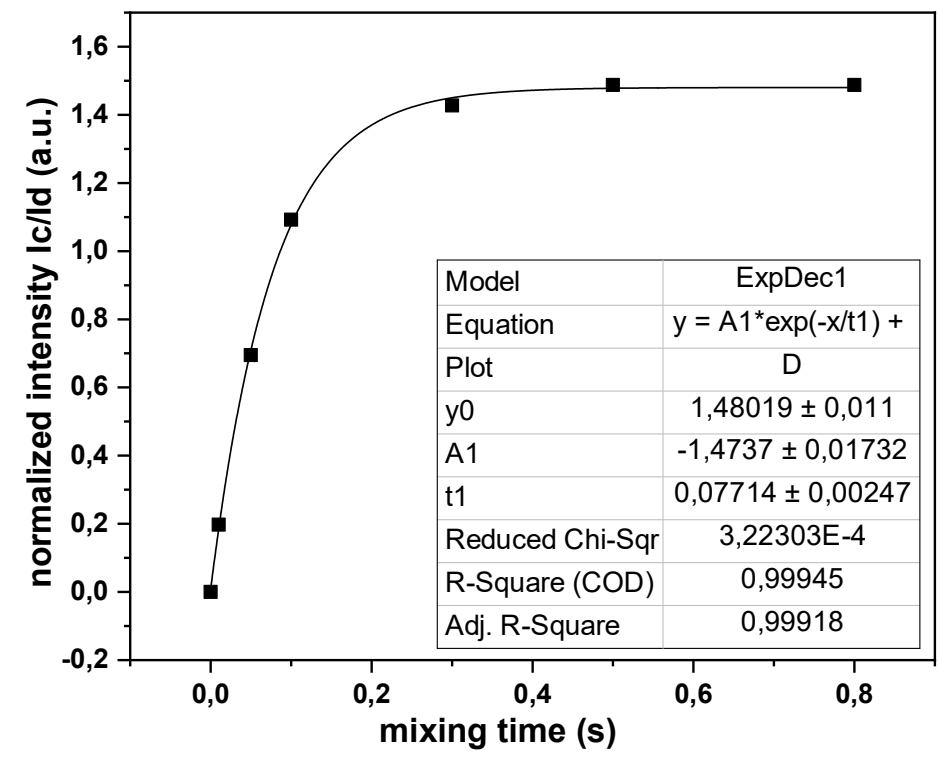

Figure S18. The ${ }^{7} \mathrm{Li}{ }^{7} \mathrm{Li}$ chemical-exchange build-up curve determined from ${ }^{7} \mathrm{Li}-{ }^{7} \mathrm{Li}$ MAS EXSY NMR spectra of MIL53(Al)@LiCoD-0.10 measured at 330 K. 


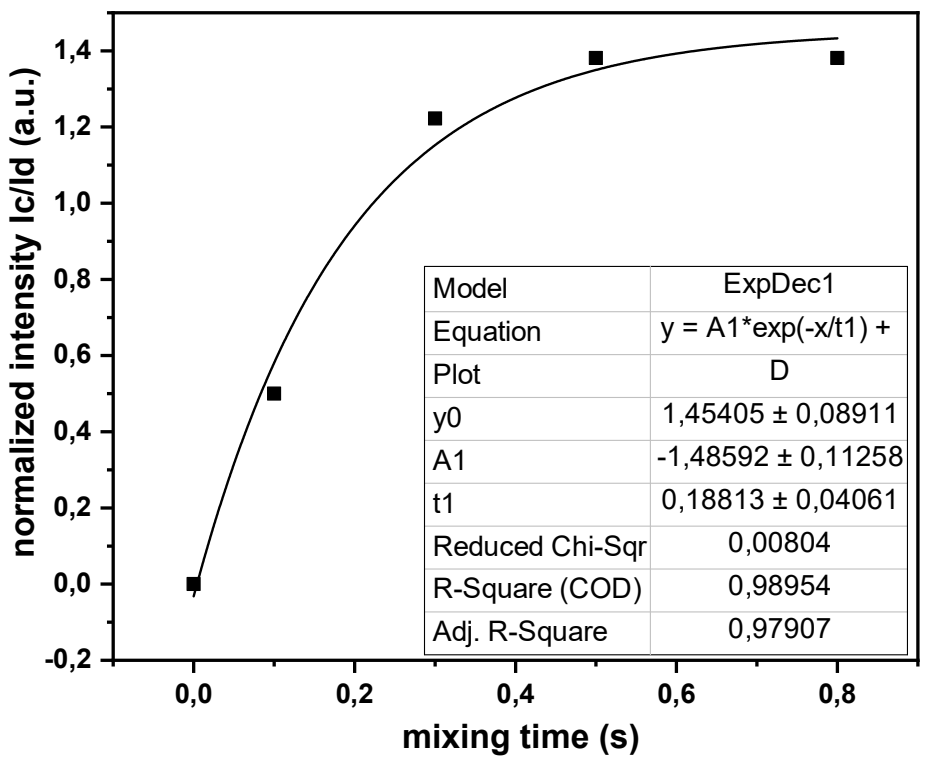

Figure S19. The ${ }^{7} \mathrm{Li}-{ }^{7} \mathrm{Li}$ chemical-exchange build-up curve determined from ${ }^{7} \mathrm{Li}-{ }^{7} \mathrm{Li} \mathrm{MAS}$ EXSY NMR spectra of MIL53(Al)@LiCoD-0.50 measured at 295 K.

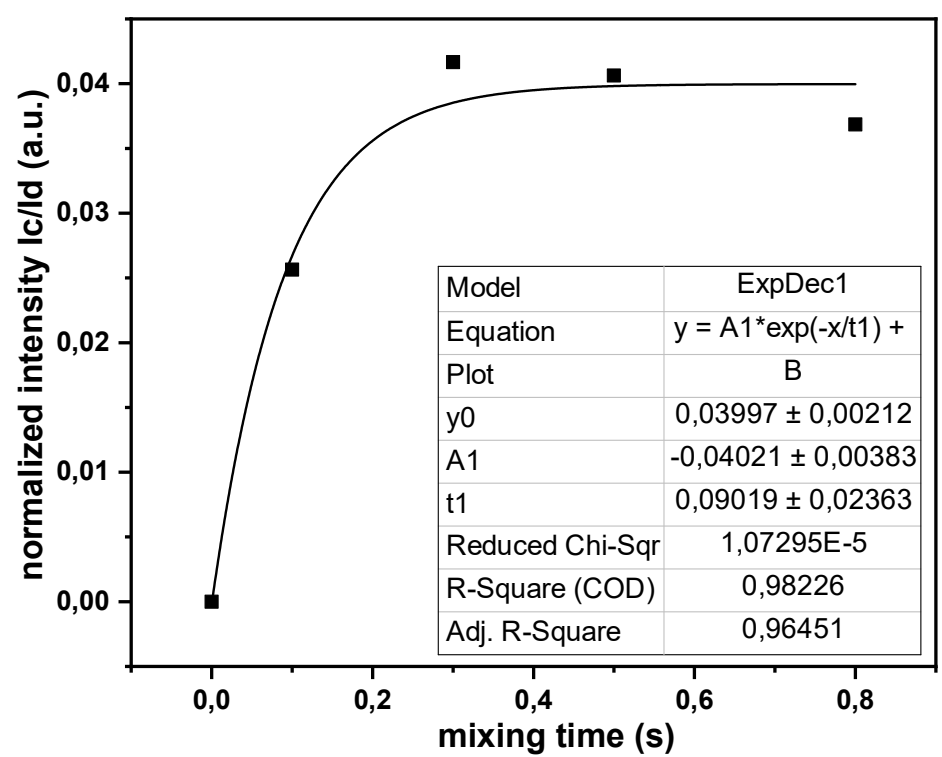

Figure S20. The ${ }^{7} \mathrm{Li}-{ }^{7} \mathrm{Li}$ chemical-exchange build-up curve determined from ${ }^{7} \mathrm{Li}-{ }^{7} \mathrm{Li}$ MAS EXSY NMR spectra of MIL53(Al)@LiCoD-0.50 measured at 330 K. 


\section{Supporting Information S9-AC conductivity measurements}

Some measured impedance data are presented (as an example) in Figure S21. The curves in complex impedance $Z_{1}-Z_{2}$ plot demonstrate a typical ionic conductivity behavior. High-frequency semicircle represents the bulk properties of the material and low-frequency tail is due to electrode polarization phenomenon at the interface. Complex impedance plots were analyzed by an equivalent electrical circuit approach using a ZSimpWin software. ${ }^{37}$ A parallel arrangement of the resistance $R$ and a constant phase element (CPE), as defined by Barsoukov and MacDonald ${ }^{38}$, was used for our fit. The resistivity $R$ obtained by the fit and recalculated $A C$ conductivity $\sigma$ are summarized in Table S2. The conductivity $\sigma$ dependence on temperature and relative humidity are presented in Figure S22. Ionic conductivity of all samples rises with increasing both temperature and relative humidity.

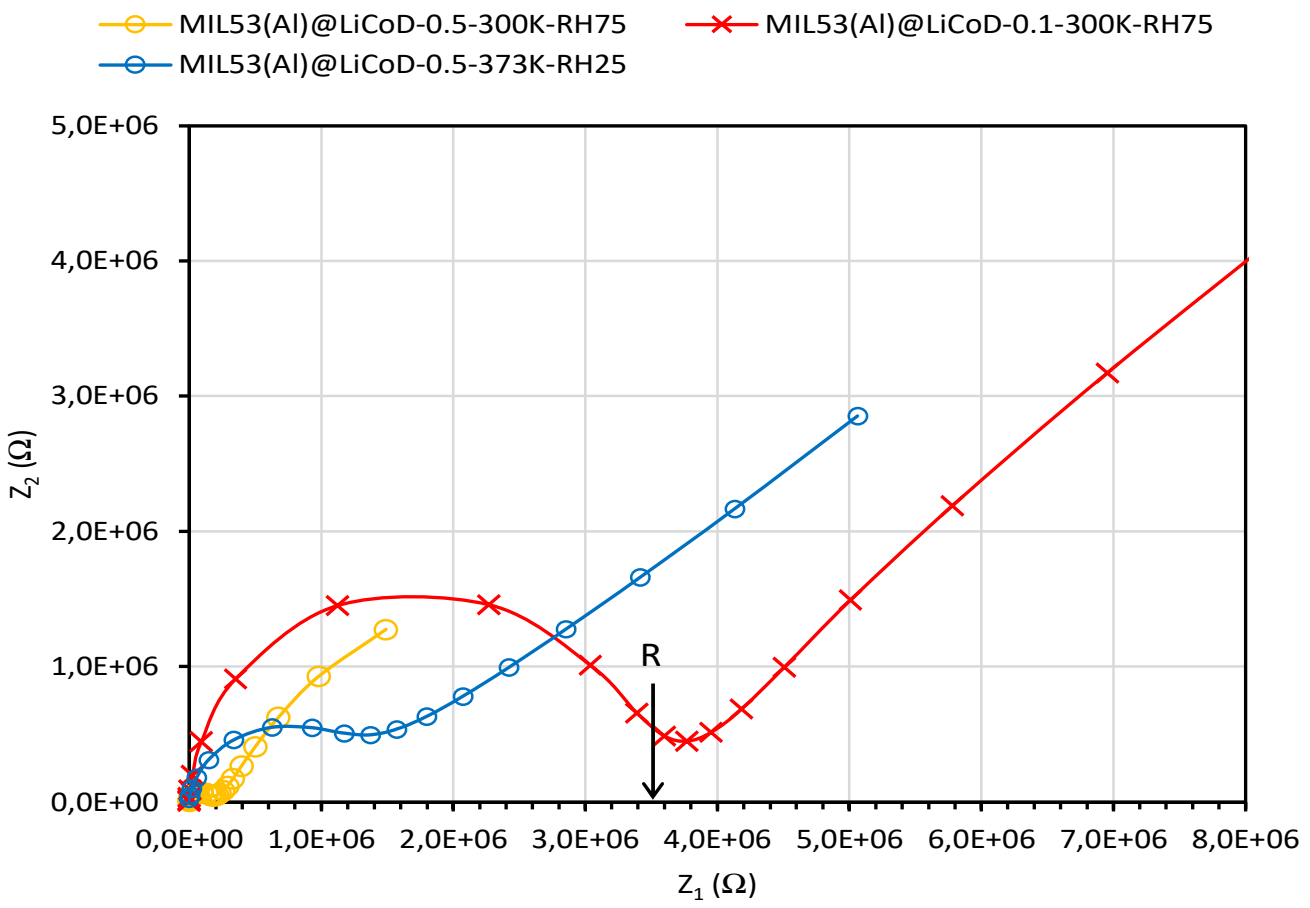

Figure S21. Experimentally obtained complex Z1-Z2 plot of MIL53(AI)@LiCoD-0.10 -(x) and MIL53(AI)@LiCoD0.50 -(o) with denoted bulk resistivity R (see text) for MIL53(Al)@LiCoD-0.10-300K-RH75 as an example.

Table S2. The resistivity R obtained by a fit and calculated AC conductivity of samples.

\begin{tabular}{lll||ll}
\hline Sample & $\mathrm{T}(\mathrm{K})$ & $\mathrm{RH}(\%)$ & Resistivity $\mathrm{R}(\Omega)$ & Conductivity $\sigma\left({\left.\mathrm{S} . \mathrm{cm}^{-1}\right)}^{-1}\right.$ \\
\hline \hline & 300 & 25 & $2,5 \mathrm{E}+09$ & $9,2 \mathrm{E}-10$ \\
MIL53(AI)@LiCoD-0.1 & 373 & 25 & $5,5 \mathrm{E}+05$ & $4,2 \mathrm{E}-06$ \\
& 300 & 75 & $3,5 \mathrm{E}+06$ & $6,6 \mathrm{E}-07$ \\
& 373 & 75 & $7,2 \mathrm{E}+04$ & $3,2 \mathrm{E}-05$ \\
& 300 & 25 & $3,3 \mathrm{E}+08$ & $4,9 \mathrm{E}-09$ \\
MIL53(AI)@LiCoD-0.5 & 373 & 25 & $1,3 \mathrm{E}+06$ & $1,3 \mathrm{E}-06$ \\
& 300 & 75 & $1,8 \mathrm{E}+05$ & $9,1 \mathrm{E}-06$ \\
& 373 & 75 & $9,0 \mathrm{E}+02$ & $1,8 \mathrm{E}-03$ \\
\hline
\end{tabular}




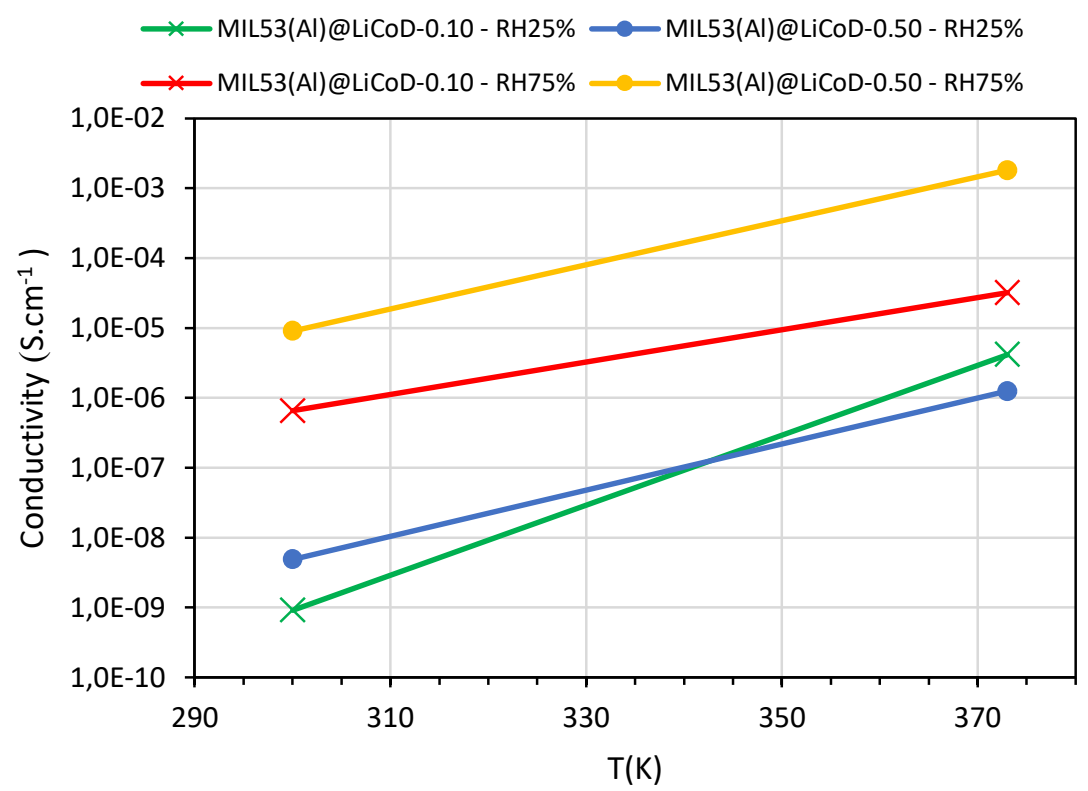

Figure S22. AC conductivity of MIL53(Al)@LiCoD-0.10 -(x) and MIL53(Al)@LiCoD-0.50 -(•) measured at 300K and $373 \mathrm{~K}$ for two different relative humidity (RH25\% and $\mathrm{RH} 75 \%)$.

\section{References:}

(37) Yeum, B.ZSimpWin1; EChem Software: Ann Arbor, USA,1999-2013.

(38) Barsoukov, E.; MacDonald, J. R. Impedance Spectroscopy, Theory, Experiment, and Applications; Wiley: Hoboken, USA, 2005. 


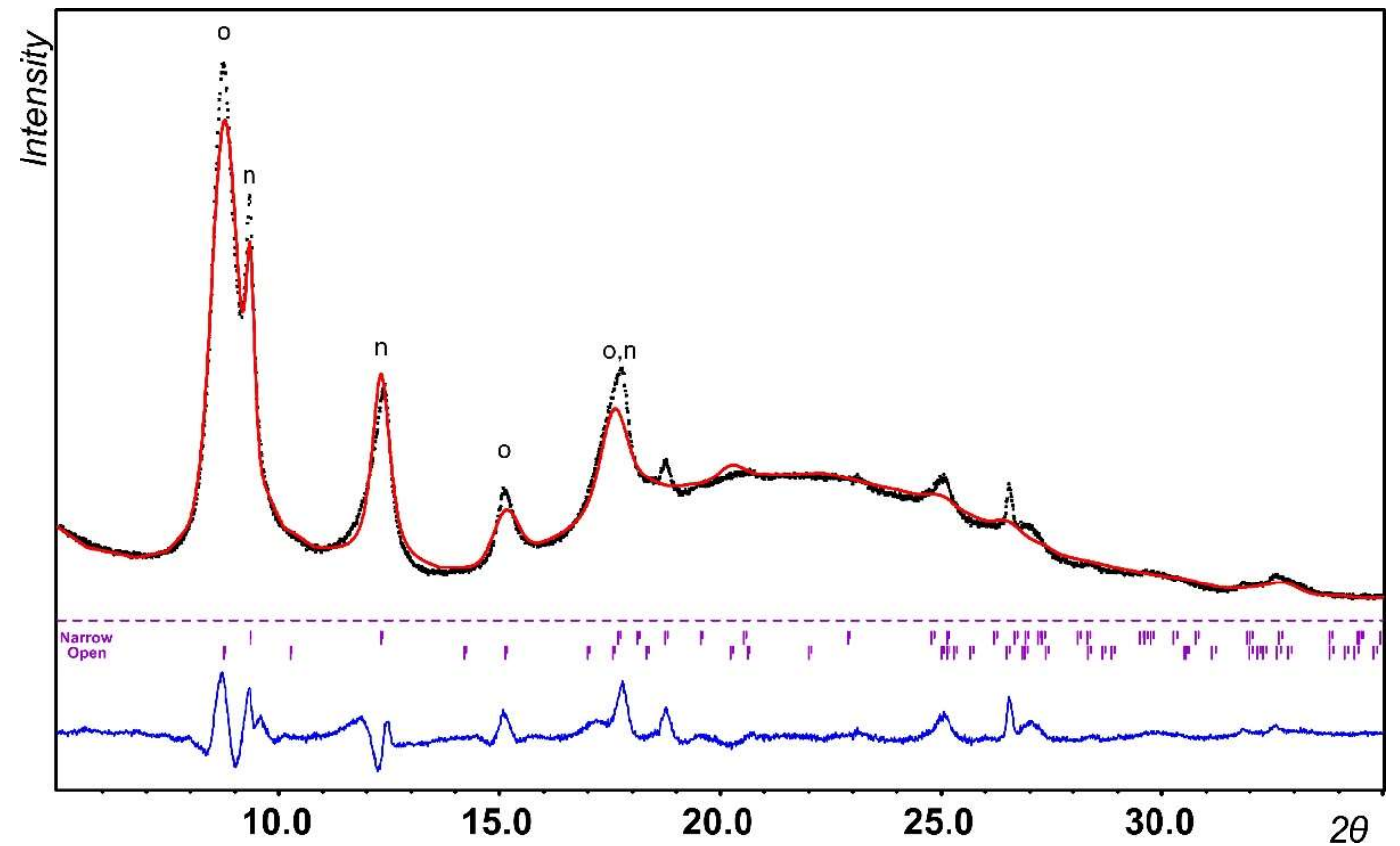

Figure S23. X-ray powder diffraction data of MIL53(AI)ht system (black dots) and the theoretical fit (red line) with positions of reflections (magenta bars). Letters ' $n$ ' and ' $o$ ' above the observed peaks indicate the presence of narrow (CCDC 220477) and open-channel (CCDC 220476) form.

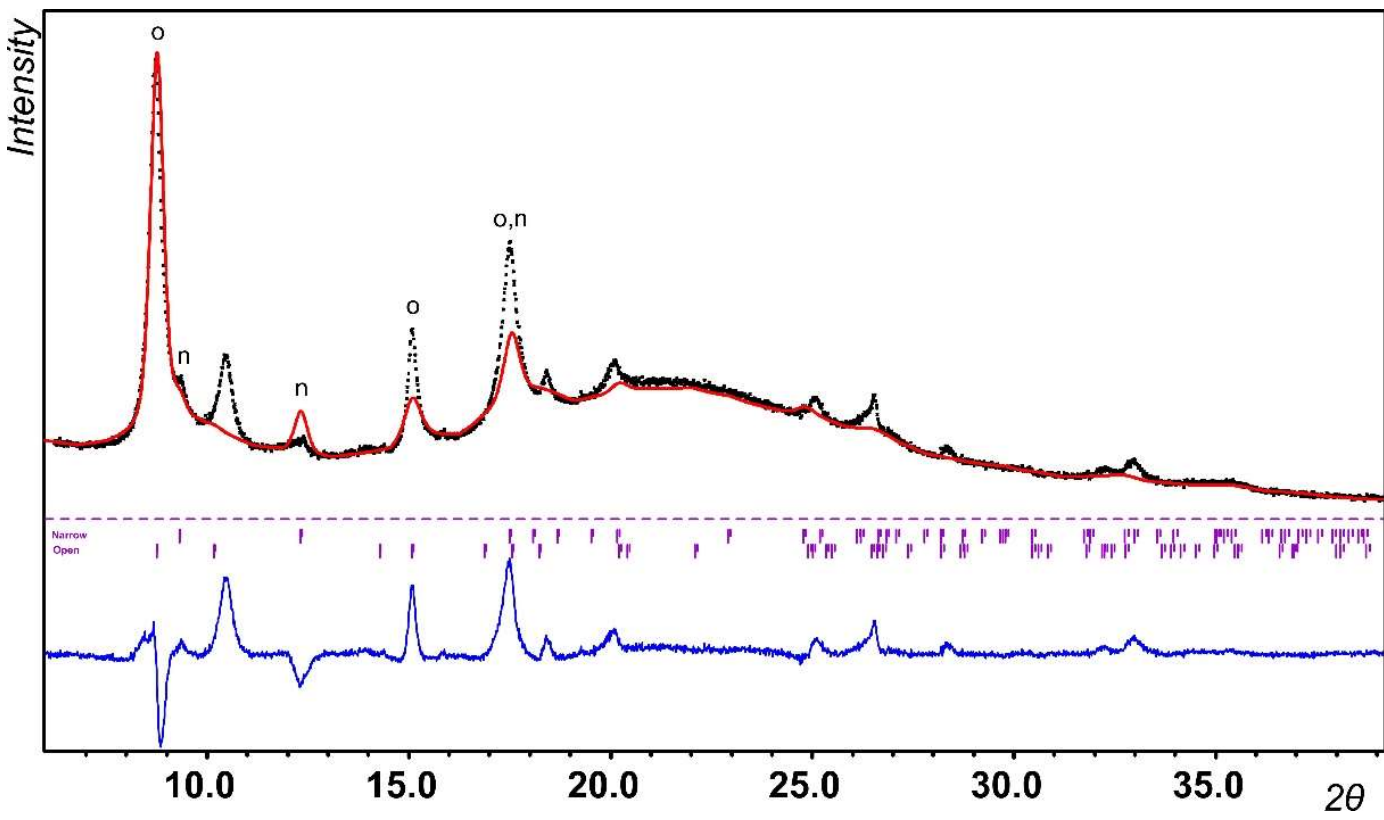

Figure S24. X-ray powder diffraction data of MIL53(AI)@LiCoD-0.10 host-guest composite (black dots) and the theoretical fit (red line) with positions of reflections (magenta bars). Letters ' $n$ ' and ' $o$ ' above the observed peaks indicate the presence of narrow (CCDC 220477) and open-channel (CCDC 220476) form. 


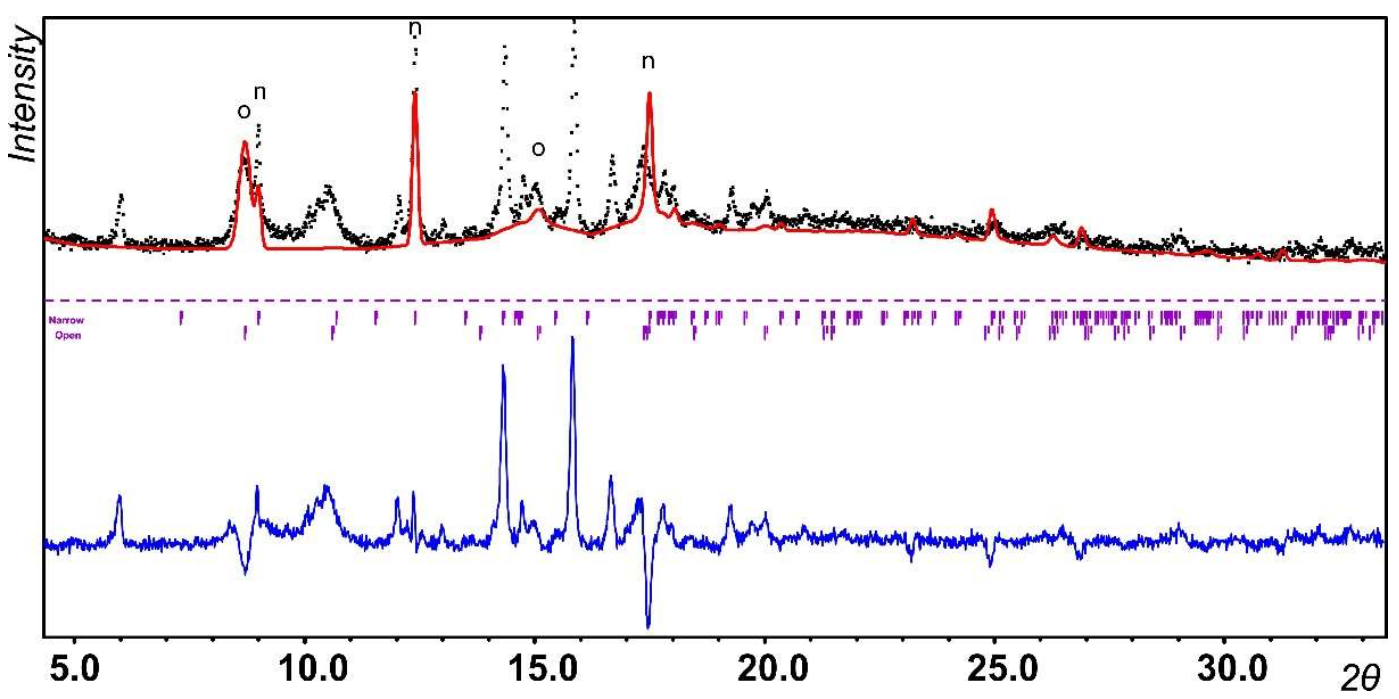

Figure S25. X-ray powder diffraction data of MIL53(Al)@LiCoD-0.50 host-guest composite (black dots) and the theoretical fit (red line) with positions of reflections (magenta bars). Letters ' $n$ ' and ' $o$ ' above the observed peaks indicate the presence of narrow (CCDC 690316, where Fe was changed to Al) and open-channel (CCDC 220476) form 